\title{
A Work Flow and Evaluation of Using Unmanned Aerial Systems for Deriving Forest Stand Characteristics in Mixed Hardwoods of West Virginia
}

Henry Liebermann

Follow this and additional works at: https://researchrepository.wvu.edu/etd

\section{Recommended Citation}

Liebermann, Henry, "A Work Flow and Evaluation of Using Unmanned Aerial Systems for Deriving Forest Stand Characteristics in Mixed Hardwoods of West Virginia" (2017). Graduate Theses, Dissertations, and Problem Reports. 6083.

https://researchrepository.wvu.edu/etd/6083

This Thesis is protected by copyright and/or related rights. It has been brought to you by the The Research Repository @WVU with permission from the rights-holder(s). You are free to use this Thesis in any way that is permitted by the copyright and related rights legislation that applies to your use. For other uses you must obtain permission from the rights-holder(s) directly, unless additional rights are indicated by a Creative Commons license in the record and/ or on the work itself. This Thesis has been accepted for inclusion in WVU Graduate Theses, Dissertations, and Problem Reports collection by an authorized administrator of The Research Repository @ WVU. For more information, please contact researchrepository@mail.wvu.edu. 
A work flow and evaluation of using unmanned aerial systems for deriving forest stand characteristics in mixed hardwoods of West Virginia

$$
\text { Henry Liebermann }
$$

Thesis submitted to the Davis College of Agriculture, Natural Resources and Design at West Virginia University

In partial fulfillment of the requirements for the degree of

Master of Science in Forest Resources Management

Jamie Schuler, Ph.D., Chair Michael Strager, Ph.D. Joseph McNeel, Ph.D.

West Virginia University School of Natural Resources Morgantown, West Virginia

2017

Keywords: UAS, drones, forest inventory, boardfoot volume, automated segmentation, eCogntion Copyright 2017 Henry Liebermann 


\begin{abstract}
A work flow and evaluation of using unmanned aerial systems for deriving forest stand characteristics in mixed hardwoods of West Virginia

Henry Liebermann
\end{abstract}

Forest inventory information is a principle driver for forest management decisions. Information gathered through these inventories provides a summary of the condition of forested stands. The method by which remote sensing aids land managers is changing rapidly. Imagery produced from unmanned aerial systems (UAS) offer high temporal and spatial resolutions and have added another approach to small-scale forest management. UAS imagery is less expensive and easier to coordinate to meet project needs compared to traditional manned aerial imagery. This study focused on producing an efficient and approachable work flow for producing forest stand board foot volume estimates from UAS imagery in mixed hardwood stands of West Virginia. A supplementary aim of this project was to evaluate which season was best to collect imagery for forest inventory. True color imagery was collected with a DJI Phantom 3 Professional UAS and was processed in Agisoft Photoscan Professional. Automated segmentation was performed with Trimble eCognition Developer's multi-resolution segmentation function with manual optimization of parameters through an iterative process. Individual tree volume metrics were derived from field data relationships and volume estimates were processed in EZ CRUZ forest inventory software. The software, at best, correctly segmented $43 \%$ of the individual tree crowns. No correlation between season of imagery acquisition and quality of segmentation was shown. Volume and other stand characteristics were not accurately estimated and were faulted by poor segmentation. However, the imagery was able to capture gaps consistently and the high resolution imagery was able to provide a visualization of forest health. Difficulties, successes and time required for these procedures were thoroughly noted. 


\section{Acknowledgments}

The field crew of the century: Kevin Tomlinson, Bart Caterino, Taryn Pifer, Alex Storm and Helen Donnelly. I have to extend an extraordinary amount of thanks to Dr. Aaron Maxwell who made the automated segmentation possible for this study. Meteorlogik Aerial Resources' Joey Kimmet made the UAS imagery happen and Angela Hentz put it all together. This was a great collaborative effort. I'd also be remiss to not extend acknowledgements to Gene's Beer Garden for providing the venue which cultivated the creativity and unwavering devotion that propelled these research efforts forward. 


\section{Contents}

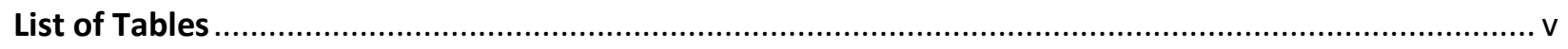

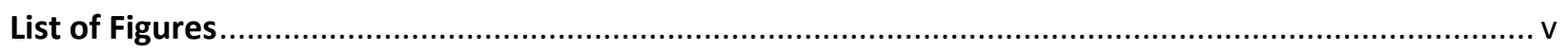

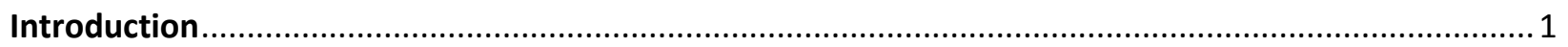

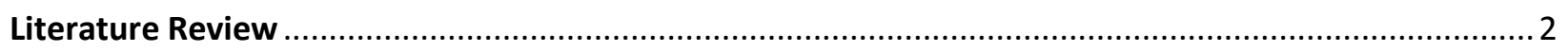

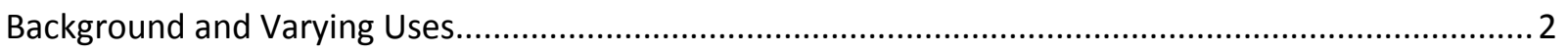

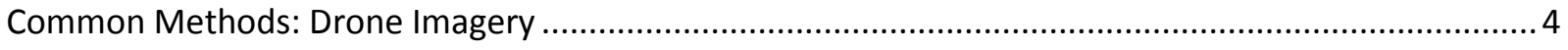

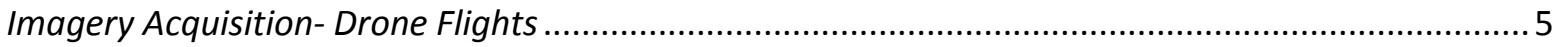

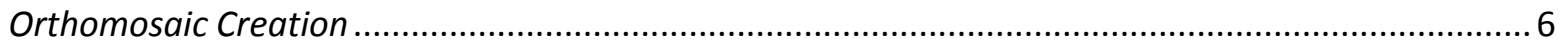

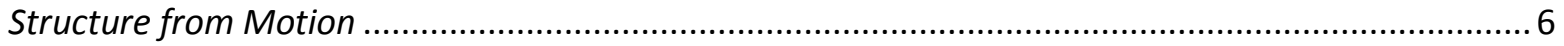

Tree Crown Segmentation and Height Measurements ................................................................ 7

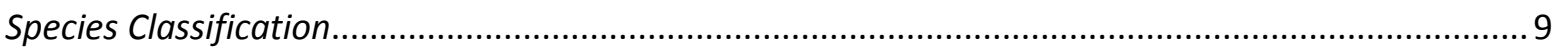

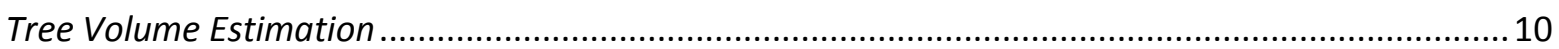

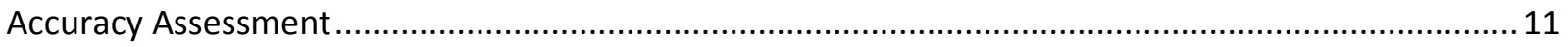

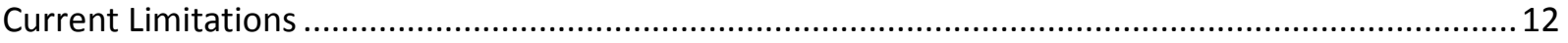

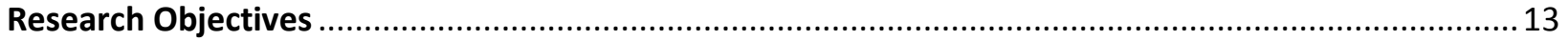

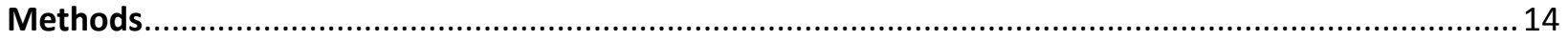

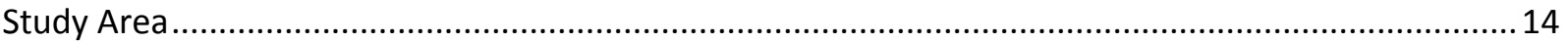

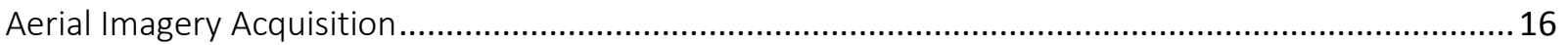

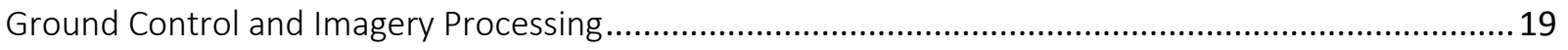

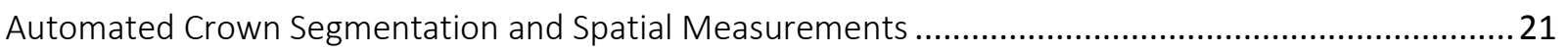

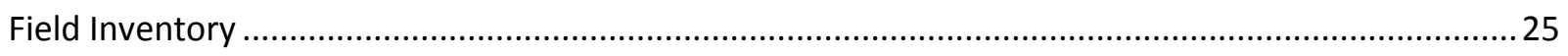

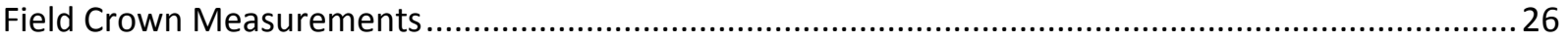

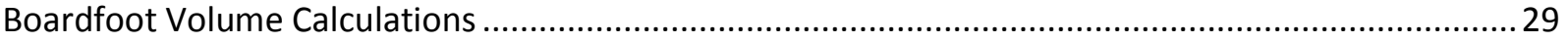

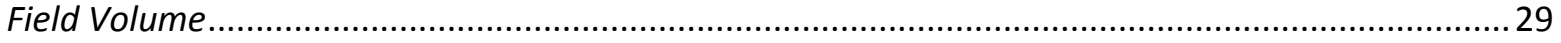

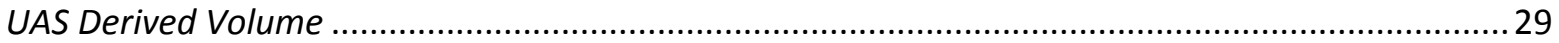

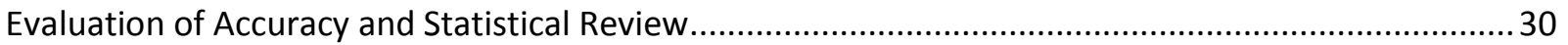

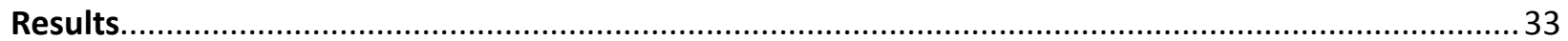

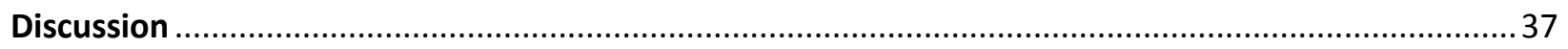

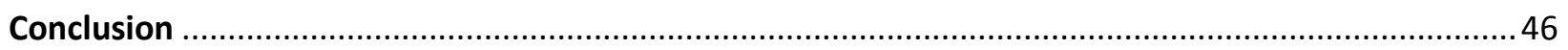

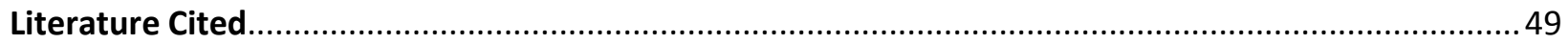




\section{List of Tables}

Table 1. Segmentation parameters for site one dominated by red maple and yellow-poplar....... .23

Table 2. Segmentation parameters for site three dominated by red maple and northern red oak............24

Table 3. Summary of imagery processing for all imagery sets.......................................................................33

Table 4. Tree crown segmentation results for all imagery and combinations.............................................34

Table 5. Boardfoot volume estimates derived from segmentations and field measurements...................35

Table 6. Summary of gap identification amongst queried gaps for all segmentations .................................36

Table 7. Summary of overall gap identification amongst for all segmentations..........................................37

Table 8. Comparison of tree species prevalence between study sites HLO and HL3 ................................40

\section{List of Figures}

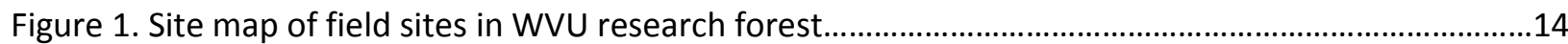

Figure 2. Forest tree species distribution by number of stems in five field sites in research forest...........15

Figure 3. Screen capture during flight of 'Map Pilot' DJI compatible application.........................................16

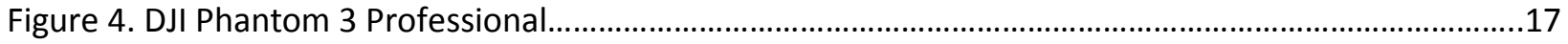

Figure 5. Flight line paths for imagery acquisition..................................................................................18

Figure 6. Example of missing data in aerial imagery acquisition................................................................18

Figure 7. Distribution of ground control and check points throughout HLO and HL3................................20

Figure 8. Ground control point target with iGage X900S-OPUS GNSS static GPS receiver.........................21

Figure 9. Comparison of LiDAR and SfM point clouds at capturing ground-level data................................22

Figure 10. Field tree crown measurement vertex arrangement around tree drip line................................27

Figure 11. Field tree crown measurement six irregular triangles created through measurement..............28

Figure 12. Field crown measurement cardinal direction measurements...................................................28

Figure 13. Example of correctly and incorrectly segmented tree crowns for visual evaluation..................31

Figure 14. Relationship between DBH and crown area from field measurements.....................................35

Figure 15. Aerial image of tree canopy $17-y e a r$ cicada damage...................................................................44 


\section{Introduction}

Science is continually being propelled forward by new technology. With the arrival of unmanned aerial systems (UAS) for citizen consumption, remote sensing has been changing rapidly (Lisein et al., 2015). Forest inventory has often used aerial imagery as a compliment for the creation of stand maps. These maps are often used in management to better understand stand layout and the spatial distribution of trees and landscape features throughout the stand from an aerial perspective. These maps are the backdrop for much of the geospatial analysis for these stands. Manned aerial vehicles are the most common method by which aerial imagery is collected. The manned flights can be expensive and cumbersome to coordinate. There are a number of reasons why UAS, colloquially known as drones, are desirable to forest managers, researchers and the like. These uses are not limited to stream mapping, orthomosaic creation, forest inventory and wildlife monitoring. The primary advantages of utilizing UAS in assisting forest inventory are the high spatial and temporal resolutions, low cost and ease of customization to project needs (Puliti et al., 2015). These advantages have the potential of cutting costs and time necessary for inventory as well as increasing accuracy.

This study provides a comprehensive evaluation of performing an automated forest inventory with an unmanned aerial system with a primary focus on the photogrammetric analysis of the imagery. The development of an applicable work flow and evaluation of the accuracy of the forest inventory metrics compared to field data are the primary aims of this study. Forest volume estimates are a primary driver of forest value in the central Appalachian Region and are a major concern of management in this location.

Unmanned aerial vehicles are defined as aerial vehicles that do not have a human occupant, have automated control and are intended to be recovered at the end of the flight (Newcome, 2004). Often the use of the terms of UAS and UAV (unmanned aerial vehicle) are used interchangeably in remote sensing literature but there is a further dimension of complexity to the term UAS. There are four 
parts to a UAS: a UAV, an aerial sensor such as a digital camera, a navigational computer, and a UAV operator (Puliti, et al., 2015). Sometimes spotters are utilized when operating the drone but are not always necessary. It appears that the term UAS is most common in literature. These systems also require the use of software to produce a useable product for data manipulation; the data are not ready to be manipulated immediately after collection. The production of a fully orthorectified mosaic with associated point cloud is necessary before further photogrammetric analysis can occur. This process can be performed in a number of different software packages.

Forest inventories provide detailed information of a forest stand. These inventories measure the extent, quantity, and condition of trees within an area (Kangas et al., 2006). This information is utilized by forest managers and researchers to make management decisions on these lands. Ground work has been the primary way to implement these inventories due to the complexities of these ecosystems. Forests vary greatly not only by the species present but by topography, complex vertical structures of tree crowns and many more. The use of aerial imagery and other remote sensing techniques allows a different and supplementary glimpse into these highly variable forests. UAS use in forestry is still young and there are limited research articles published in this field (Puliti, et al., 2015).

The intent of this study was to develop a work flow that is efficient in time and money for land managers to inventory forests using UAS technology. The use of UAS in forestry applications may be a way to cut time and costs in forest inventory. This study focused on the segmentation and stand characteristic metric development and did not proceed with species classification of segmented tree crowns.

\section{Literature Review}

\section{Background and Varying Uses}

UAVs are not new technology. The origins of these technologies dates back to World War I. Early prototypes, developed by the United States Army and Navy, were developed to carry bombs to enemy 
trenches but were found to be too difficult to control and recover to be fully implemented. The use of radio signals and improved engineering fueled improvement in the technologies (Keane \& Carr, 2013). Through the decades, UAV technology has developed greatly and the applications of these tools has increased significantly. Drones are still often used in military action, as is popularized by media coverage, but UAVs have more uses beyond carrying bombs and being used as target practice.

UAVs are being utilized in situations where traditional remote sensing methods (satellite imagery or manned aerial vehicle imagery acquisition) are too expensive, inflexible or too coarse of resolution (Whitehead et al., 2014). Two important advantages of UAV imagery in forestry applications are the very high spatial and temporal resolution (Mischez et al., 2016). The resolution of the imagery produced from UAVs can be customized to meet needs of research, management, surveying and more. This flexibility is extremely utilitarian when designing projects. For instance, if one wanted to capture the sequence of emergence of flowers by tree species, UAV technology could be flown cheaply and easily over small areas in an automated fashion to capture these phenomenon over time. This information is observable on a very small local scale with this technology. Another primary advantage of UAV imagery over the traditional methods of acquisition is the significant affordability. Although it is difficult to compare prices directly due to the variation in markets and needs of projects, it is well cited in literature, that this method is cheaper than the conventional methods (Getzin et al., 2012; Wallace et al., 2012a; Puliti et al., 2015; Hernandez et al., 2016).

Methods for utilizing UAVs for forest fire detection surveys through corrected true color images are being developed and are thought to be an integral time saving tool in preventing wildfires (Cruz et al., 2016). Common uses in remote sensing, outside of forestry, for UAVs include monitoring changes in artic glaciers, health monitoring in agricultural crops, counting wildlife and other animal populations, and mapping river habitat (Whitehead et al., 2014). These applications will not be discussed in great detail in this report. 
Imagery acquisition and photogrammetric analysis have seen resurgence with the use of UAS and are likely the most common uses of UAS in forestry applications, but are not the only method available. Light detection and ranging (LiDAR) scanners have been developed for UAVs. Although LiDAR data have become commonplace in remote sensing practices, the application of UAV-borne LiDAR sensors is quite new (Wei, 2016). UAV-borne LiDAR scanners have been used to differentiate individual crowns, calculate tree height, to find crown size and eventually producing volume measurements with one dataset (Wallace et al., 2012b). These practices are important improvements in the field of forest remote sensing but LiDAR mounted on the conventional manned aerial vehicles is still the most commonly accepted method to utilize this technology. The major focus in literature is the use of photogrammetric methods to analyze UAS imagery due to the high resolution and improvements in technology.

\section{Common Methods: Drone Imagery}

Generally, the use of a broad spectrum of photogrammetric analyses are the primary way drone imagery is utilized. It is important to examine the previous aims of the projects that have been successfully established and implemented to begin to fully understand the utility of these tools. Georeferencing

Ground control is commonplace in the georeferencing process of remote sensing techniques. Ground control points (GCPs) allow images to be tied to real world locations. This can be performed by relating known areas on maps to the same areas in the imagery, which is the quickest and easiest method. With drone imagery, the resolution is often too fine to perform accurate rectification this way due to the coarseness of historic map scales, so manual installation of ground control points is necessary (Lillesand et al., 2014). Manually installed ground control points usually consist of a target laid in areas that are highly visible from the aerial images. Highly accurate GPS coordinates are then taken at these locations to complete the georeferencing process. This is crucial step in UAV imagery. Often the ground 
control point installation process is a highly intensive process taking many hours and attempts to correctly identify well distributed positions for targets.

Alternatively, directly georeferencing UAS derived imagery without the use of intensive ground control points is possible. In Turner et al. (2014), data were collected by UAS with a simple navigationgrade GPS unit onboard for spatial referencing. The capture of each image was triggered by an automatic trigger and the onboard GPS unit assigned a spatial position to each image. This study was performed in lettuce field in Australia and produced spatially accurate mosaics with an error of about $0.36 \mathrm{ft}$. The use of an inertial measurement unit (IMU), devices capable of measuring an object's force and rate of movement, shows promise in direct georeferencing in forest settings with an average RMSE of $0.85 \mathrm{ft}$ (Wallace et al., 2012b). Emerging science has been shown that real-time kinematic (RTK) precise point position (PPP) systems can perform aerial triangulation of ground features to subcentimeter accuracy for horizontal measurements and centimeter accuracy in vertical measurements (Shi et al., 2016).

Imagery Acquisition- Drone Flights

Drone flights are performed with flight line overlap of around 80 percent to ensure sufficient coverage of the ground (Haala, 2013). This amount of overlap is greater than the overlap of the flight lines of conventional imagery acquisition (about 50-60\%) due to the low flight altitude. Low flight altitude produces a much higher sensitivity to motion and can cause variability in single flight paths that is greater than that of the conventional method. The greater overlap is intended to reduce these errors.

There are many different models of drones used in these applications but often the multi-copter (many rotors) varieties are used in small acreage applications which is typical for forestry applications (Puliti et al., 2015). The multirotor UAVs have slower flight speeds, but usually allow for more control over flight line overlap (Puliti et al, 2015). Fixed-wing drones have been used for large areas but these vehicles are far more expensive (Lisein et al., 2015). 
For photogrammetric analysis, consumer grade, true-color digital cameras are the most common attachment on UASs. However, a wide array of sensor attachments are available. Multispectral sensors and thermal imaging sensors have been attached to UAVs to gather information on vegetation (Berni et al., 2009).

The automation of flight paths is one of the principle luxuries with the utilization of UAVs. Although a pilot is necessary to control the drone in some cases and respond to problems, much of the process is controlled by software once a flight path is programmed. This autonomous feature of drone flight paths and data collection makes UAS great for multi-temporal datasets due to the ability to capture the same area with great detail as many times as is necessary.

\section{Orthomosaic Creation}

With a flight path overlap of around 80 percent, the number of images produced by UAS is quite high. Photos need to be georeferenced, orthorectified and stitched together into a mosaic before the photogrammetric analysis of the entire area can take place. There are a number of software packages that specialize in manipulating these photos and producing a usable product. The preferred software package throughout UAS imagery literature is Agisoft Photoscan Professional (Agisoft LLC, St. Petersburgh, Russia) image processing software. Photoscan has been compared to other software packages in performing georeferencing, mosaicking and orthorectification such as Pix4D (Pix4D, Lausanne, Switzerland) a cloud-based web imaging processing service. Photoscan produces very accurate results and has superior ability to accurately and efficiently process UAS captured imagery (Turner et al., 2014).

\section{Structure from Motion}

Structure from motion (SFM) models are created from UAV imagery via traditional photogrammetric methods. These images, when viewed stereoscopically, have the same point appear in multiple images. In the case of UAV imagery with $80 \%$ overlap, these points can occur in a great number 
of images which allows for a more accurate model of common points in 3-D space (Wallace et al., 2016). The models, or point clouds, that are derived from UAS imagery differ from LiDAR due to the fact that LiDAR sensors create 3-D models based on the time it takes for an emitted laser pulse to return to the scanner after hitting an object, as well as this pulse's intensity upon return. SfM and LiDAR canopy height measurements were shown to be highly correlated in Messinger et al. (2016). These SfM models can be a great asset in further image analysis, allowing users to manipulate the data much like they would LiDAR data.

SfM models have been used to create a 3D representation of forest hauling roads in the Czech Republic for evaluation of the condition of the wearing surface of these roads (Hruza et al., 2016). This method of evaluating forest roads was shown to be highly detailed, accurate and efficient. A principle application of these SfM in forestry applications has been in the creation of canopy height models (CHM). Much of the literature suggests that it is important to consider using LiDAR and SfM to aid in remotely sensed forest inventories and the model that is chosen is based on project needs. Cost is also prohibitive to the use of LiDAR. It is suggested that SfM is able to produce data with greater spatial coverage than LiDAR (White et al., 2013). However, Wallace et al. (2016), found that SfM was not capable of producing reliable ground elevation data under dense forest canopies, which suggests that it is best to use LiDAR and SFM in tandem to produce canopy heights.

\section{Tree Crown Segmentation and Height Measurements}

Many of the measurements performed on UAS derived data do not differ greatly from the measurements provided from conventionally attained aerial imagery, but are of such high resolution that they open up many new opportunities in photogrammetric analysis. With LiDAR able to produce efficient and accurate ground elevations and the UASs capable of capturing a vivid picture of the canopy structure, these two can be subtracted in order to estimate tree heights. These heights can be assigned by pixel or to objects that are created across the landscape. 
The difficulty then lies with segmenting out individual tree crowns from the imagery or point clouds to assign specific heights to the individual tree crowns. The tried-and-true method of performing segmentation is by heads-up digitizing individual tree crowns from the imagery and producing polygons across the area of interest. With the high resolution of UAS derived imagery, this can be done but would be time consuming. A number of methods have been developed using the point cloud, either SfM or LiDAR, for tree-scale segmentation. With point cloud returns, the user can visualize the structure of each individual tree and then segment these trees. A common method to segment crowns is to utilize a local maxima point from the point cloud canopy height model throughout the study area (Brandtberg et al., 2003; Tiede et al., 2005; Kwak et al., 2007; Jing et al., 2012; Zawawi et al., 2015). These local maxima are most commonly the highest points of each tree crown, heights can be calculated for these local maxima points. Algorithms based on tree height and crown size have been used to create tree crown polygons from these local maxima (Tiede et al., 2005). Commonly, these local maxima are used in conjunction with watershed segmentation process in ESRI ArcMap, treating each local maxima as essentially a pour point and the tree crowns would then represent small drainages, the valleys being the shadows at the edges of each tree crown or the gaps between tree crowns (Kwak et al. 2007; Jing et al. 2012; Zawawi et al., 2015).

Object-based image analysis (OBIA) is another technique used to improve the automation of the segmentation using imagery instead of just using point clouds alone. This approach creates spectrally homogenous regions called objects and is very effective when applied to images with high spatial resolution (Husson et al., 2016). Segmentation using winter leaf off images have been shown to produce the greatest contrast between ground and tree canopies when using a software package eCognition (Trimble Geospatial, Munich, Germany) (Kuzmin et al., 2017). Automated segmentation has been studied in umbrella pine (Pinus pinea) plantations in Portugal using eCognition software (Hernandez et al., 2016). The eCognition feature extraction software is becoming frequently cited as a method to 
automate the segmentation portion of photogrammetric analysis. The software allows for full automation or for partial automation where the user has control over certain segmentation parameters. A summary of accuracy using eCognition will be addressed later in this review.

Remondino et al. (2014) showed the quality and time necessary for processing imagery can be affected by quality of images, noise in the imagery, low radiometric quality, shadows as well as shiny or textureless objects in both aerial imagery applications and 3-D building models. These differences can affect the quality of the point cloud generated or the feature extraction process entirely (Remondino et al., 2014).

\section{Species Classification}

Each forest species, or group of species, has a unique spectral signature (Cochrane, 2000; Key et al., 2001; Burkholder et al., 2011; Dalponte et al., 2013). These unique signatures are interpreted from reflectance over multiple spectral bands. These signatures in certain bands allows a user to interpolate species. It is less common to utilize spatial properties in the classification of species. These properties include texture, pattern, tree height, and side shape (Zhang et al., 2016). Zhang et al. (2016), used side shape for species classification with relative accuracy in British Columbia, Canada. However this would be difficult in fully stocked forest stands.

Now that LiDAR scanning has become commonplace, new methods have been developed for species classification using these data. The amount and intensity of returns to the LiDAR sensor allow one to discriminate between species with classification accuracies of up to 95\% (Kim et al., 2009; Orka et al., 2009; Suratno et al., 2009). Photogrammetric methods to infer species are not commonly used over large areas of forest stands as these methods are difficult to automate. But classification has been shown to be successful in boreal forests using high resolution winter imagery using an OBIA approach (Kuzmin et al., 2017). 


\section{Tree Volume Estimation}

The two required metrics to estimate tree volume is a diameter at breast height (DBH) and a merchantable height. After the height and species data are collected for each of the segmented tree crowns, crown area can be calculated once these files have been converted to ESRI shapefiles. Tree crown areas and their relationship to tree stem diameter are a historically well studied allometric relationship in the field of forestry (Lockhart et al., 2005). These relationships are summarized for a number of species in Europe by Hemery et al. (2005). Crown radius and DBH relationships have been shown to be highly correlated for southern bottomland species such as Carya illinoinensis $\left(r^{2}=0.87\right)$ and Quercus texana $\left(r^{2}=0.84\right)$ in Lockhart et al. (2005). For species in the Appalachian region of Tennessee, Gering and May (1995) found that yellow-poplar, Quercus and Carya had highly correlated relationships between crown radius and DBH $\left(r^{2}=0.93,0.85\right.$, and 0.85 respectively). Gering and May (1995) also compared relationships of DBH from aerially measured tree crown radii producing an $r^{2}$ of 0.67 for Quercus and Carya and $\mathrm{r}^{2}$ of 0.85 for yellow-poplar. These relationships often need to be reassessed for very specific sites and species as the relationship can change based on relationships with surrounding species and growing conditions (Lockhart et al., 2005). Management practices influence the crown shape as well. For example, thinned and unthinned crowns will have different relationships (Medhurst \& Beadle, 2001).

Merchantable height of a tree is important for in estimating the overall board foot volume of the trees. The methods by which merchantable height is derived from remotely sensed data is not well defined. There are only a few reports explaining how to derive merchantable height from total height (e.g. Honer, 1964; Ek et al., 1984. Ek et al. (1984) showed a reasonable relationship (mean error difference in height of $7.28 \mathrm{ft}$ ) between merchantable and total height across species of the Lakes States. Models have been created for specific species like Norway spruce (Picea abies) and Scots pine (Pinus sylvestris) using diameter and total height (Puliti et al., 2015). Like total height, merchantable height is highly correlated with $\mathrm{DBH}$, allowing one to estimate merchantable height values from 
diameter measurements for various species (Brooks \& Wiant, 2006). The development of localized models to predict merchantable height from either total height or DBH appears to be the most appropriate fit at this time.

\section{Accuracy Assessment}

The report that most closely resembles the entire workflow of a full forest inventory from start to finish utilizing UAS is Puliti et al. (2015). Their study utilized UAS imagery and ground reference data to create linear models to fit all metrics necessary for forest inventory. Photogrammetric methods were utilized for tree crown segmentation. Their study produced RMSE for a number of forest inventory metrics: dominant height $=2.3 \mathrm{ft}$; stem number $=218 \mathrm{stems} / \mathrm{ac} ;$ basal area $=19.6 \mathrm{ft}^{2} / \mathrm{ac}$; and stem volume $=166.8 \mathrm{ft}^{3} / \mathrm{ac}$. The height measurements were found by subtracting the SfM point cloud canopy height form the LiDAR derived ground elevation to get tree heights.

For other studies, individual metrics like tree crown segmentation, the accuracies have been quite high. Kuzmin et al. (2017) produced segmentation and classification of three forest species at an accuracy of $81.9 \%$ in managed timberland forests of northern Finland primarily composed of Norway spruce, Scots pine and downy birch (Betula pubescens). In Portugal, Hernandez et al. (2016) produced feature detection of tree crowns at an astounding accuracy of $100 \%$ in umbrella pine plantations managed with varying treatments. Wallace et al. (2016) produced individual tree height measurements with LiDAR to an RMSE of $3.0 \mathrm{ft}$ in a small (32.81 yd x $54.68 \mathrm{yd}$ ) rectangular plot of dry, sclerophyll eucalyptus forest land with the primary species being Eucalyptus pulchella. Near Oslo, Norway, Orka et al. (2009) produced an accuracy of $88 \%$ in species classification in a forested stand dominated by Norway spruce with few deciduous species occupying the site that had not been harvested since the 1940's. Deng et al. (2016) showed a $20 \%$ decrease in segmentation accuracy for stands dominated by deciduous broadleaved trees compared to stands dominated by coniferous individuals near Nagano, Japan. This study noted the difficulty of segmenting broad-leaved trees compared to coniferous 
individuals due to the dispersive crown structure of deciduous trees which resulted in multiple segments per individual.

It is important to note that the validation of image segmentations is very difficult (Varo-Martinez et al., 2017). Accuracies were analyzed in studies that had small research areas and extensive reference data comprised of ground georeferenced individual trees or remotely mapped tree crowns. It is common to utilize a method of polygon matching in which the difference between segmented polygons and reference polygons is calculated, leaving the user a goodness of fit of the estimated object (Clinton et al., 2010). It is less common in literature to evaluate the accuracy of these segmentations when no reference data are available, such as for areas over larger land areas. Although it is shown in some studies that having a one-to-one relationship between reference data and segments is considered a requirement (Yang et al., 2016), visual evaluation of the segmentation results can be acceptable when reference data are not available (Yang et al., 2016).

The use of eCognition Developer software was applied in a general land cover classification method using satellite imagery where it would be unfeasible to collect large swaths of reference data (Haque et al., 2016). The authors visually evaluated the quality of segmentations instead of comparing them directly to reference data using a minimum threshold of fit; not accepting objects that were highly over or under segmented their intended target.

\section{Current Limitations}

The creation of a fully automated workflow for UAS derived forest inventory makes this approach appealing to managers and individuals who are not on the so-called "front lines" of this research. The automation of the drone flights, rectification, and ultimately the segmentation and measurements makes these methods highly appealing. Past studies have addressed areas of interest that lacked complexity in species, variations in stand vertical structure, stand density and topographic variation. This lack of complexity of study areas is a distinct limitation of past research. 
The studies that have contributed to the collective knowledge of forest inventory performed by UAS have primarily been performed in areas with only marginally complex forest systems. These systems often lack complexity in species richness, topography, and vertical structure. Many of the studies have been performed in boreal forest conditions (Getzin et al., 2014; Puliti et al., 2015; Kuzmin et al., 2017). Other studies have focused on areas with very few forest tree species (e.g. pine plantations, forests with open canopies and sparse, dry forests) (Liesin et al., 2015; Mikita et al., 2016; Hernandez et al., 2016; Wallace et al., 2016). These study areas with only a few species have greatly differing crown shapes and sizes, often with little crown overlap, allowing for easier data extraction (Michez et al., 2016). It has also been addressed that research efforts have not been focused on deciduous hardwood cover due to the complexities of the canopy (Ayrey et al., 2017). The interwoven crowns make segmentation and classification difficult in these deciduous hardwood forests (Ayrey et al., 2017).

\section{Research Objectives}

The primary aim of this project was to develop a simple and replicable work flow to perform inventory in mixed hardwood stands using UAS technology and associated software. The intent of this project was to use drone captured images to produce high resolution imagery which can then be used to segment tree crowns and produce a summary of forest stand characteristics. Forest stand characteristics derived from UAS imagery were compared to values from field validation surveys. Differences in forest stand characteristics were evaluated between imagery acquired in different seasons (summer and fall). The methods in this project have the potential to reduce time and capital spent on forest inventory and aid forest managers and researchers in future goals. 
Methods

Study Area

This study was conducted on the West Virginia University (WVU) Research Forest, 14 miles east of Morgantown, WV, USA. The Research Forest is primarily a continuous forested property of 7, 654 acres. This forest is typical of mixed upland hardwoods within the Appalachian Plateau.

Five sites were targeted within the University Forest for their representation in species composition, vertical structure and topography of the forest. Access was also integral in dictating site selection (Figure 1). The average area of the five research sites was 28 acres with a total area sampled of 141 acres. The species composition of these research sites was generally consistent with the composition of the forest as a whole (Figure 2). Yellow-poplar (Liriodendron tulipifera L.), various oak species (Quercus spp.), and red maple (Acer rubrum L.) were the most frequently encountered species.

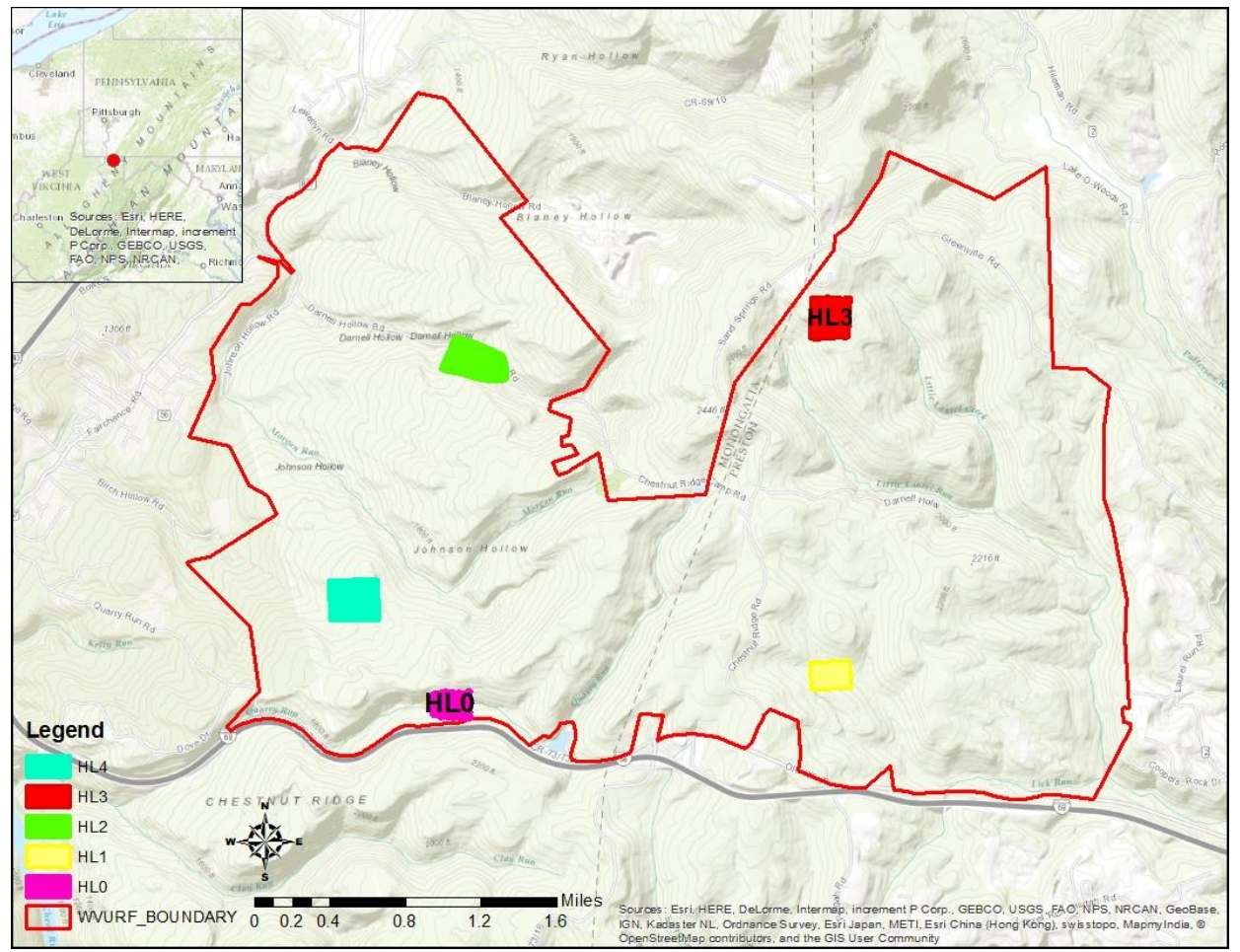

Figure 1. Site map of the WVU research forest. The five research sites are highlighted within the boundary of the forest. The location of the forest within the Mid-Atlantic region is displayed in the above data frame. 


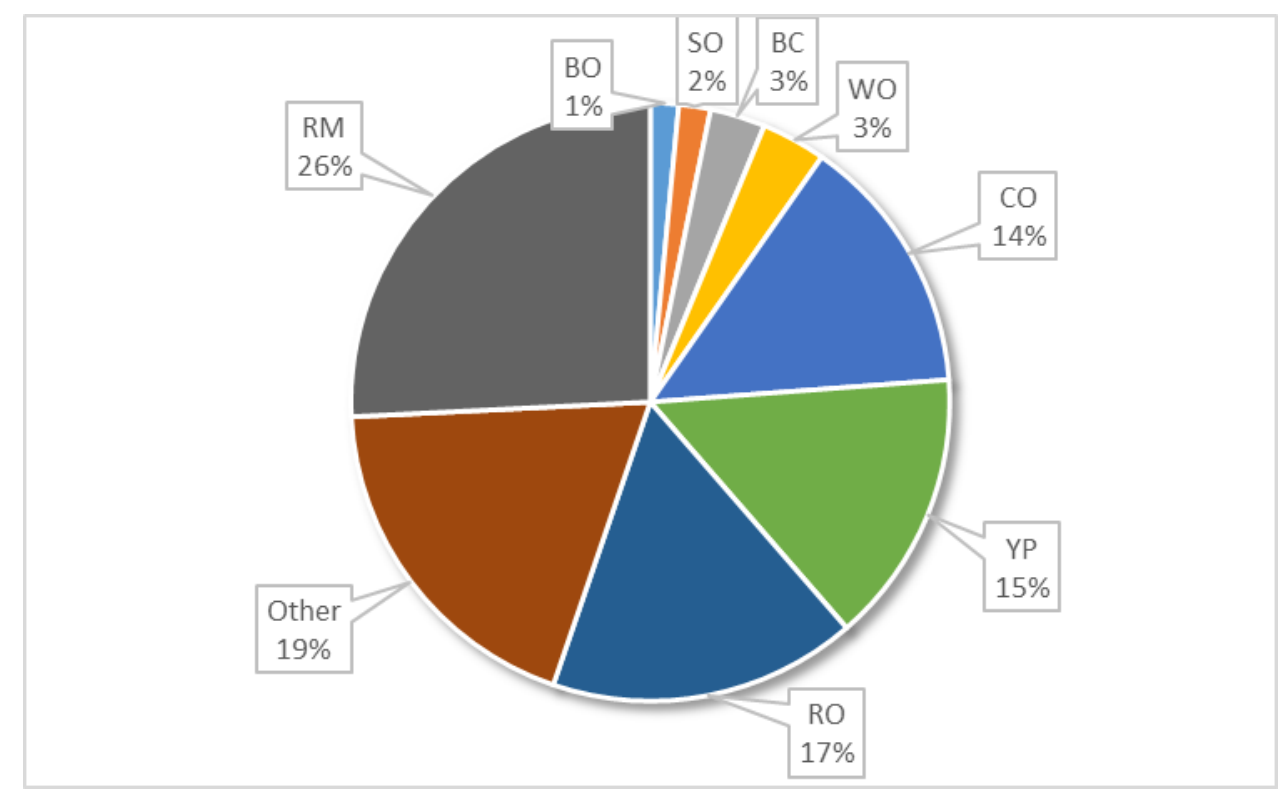

Figure 2. Species distribution by total number of stems greater than four inches $\mathrm{DBH}$ within the five research areas of the $\mathrm{WVU}$ research forest. $\mathrm{RM}=$ red maple; $\mathrm{BO}=$ black oak (Quercus velutina Lam.); $\mathrm{SO}=$ scarlet oak (Quercus coccinea Munchh.); BC = black cherry (Prunus serotina Ehrh.); WO = white oak (Quercus alba L.); CO = chestnut oak (Quercus montana Willd.); YP = yellow-poplar; RO = northern red oak (Quercus rubra L.).

Two of the sites were of primary interest. For these, a complete dataset of summer and fall imagery was collected. The HLO site was about 19 acres and was located in the southwest side of the WVU Forest and is transected west to east by the perennial stream Quarry Run with the southern extent of this site being Monongalia County Route $73 / 73$. The elevation of this site ranged from $1,758 \mathrm{ft}$ to $2,234 \mathrm{ft}$. The southern plots have predominately a north facing aspect and the northern plots have predominately a southern facing aspect. This aspect change is due to the dissection of the site by Quarry Run.

The second site (HL3) was located in the northeast portion of the WVU Research Forest, east of Sand Springs Road. This site is transected, north to south, by a gas pipeline right of way and contains a 1.15 acre field near the center of the site. The total area of this site was about 29 acres and the elevation ranged from 2, $319 \mathrm{ft}$ to $2,536 \mathrm{ft}$. The aspect of this site was south to southwest and had very gentle terrain besides the southeast corner containing a small boulder field and a large slope change. 
Aerial Imagery Acquisition

Aerial imagery was acquired by University subcontractor Meteorlogik Aerial Resources from

Morgantown, West Virginia in 2016. The five research sites were identified in collaboration between both WVU researchers and Meterologik Aerial Resources. These five areas were flown with a DJI

Phantom 3 Professional Quadcopter UAV (Figure 3). This common, consumer grade, drone carried a 1/2.3" CMOS true-color sensor capable of $4 \mathrm{~K}$ video recording and still images of 12.4 Megapixels. The sensor was stabilized by a three-axis gimbal (pitch, roll, yaw). Flight software used was the application Map Pilot for DJI (Drones Made Easy, San Diego, California). This application is downloadable onto a smartphone. The application controlled the area of interest, flight lines, flight speed, elevation above the terrain and many others (Figure 4). The application, in conjunction with the DJI drone products, creates a nearly fully automated aerial imagery data collection system. Each site was flown multiple times to collect summer and fall imagery.

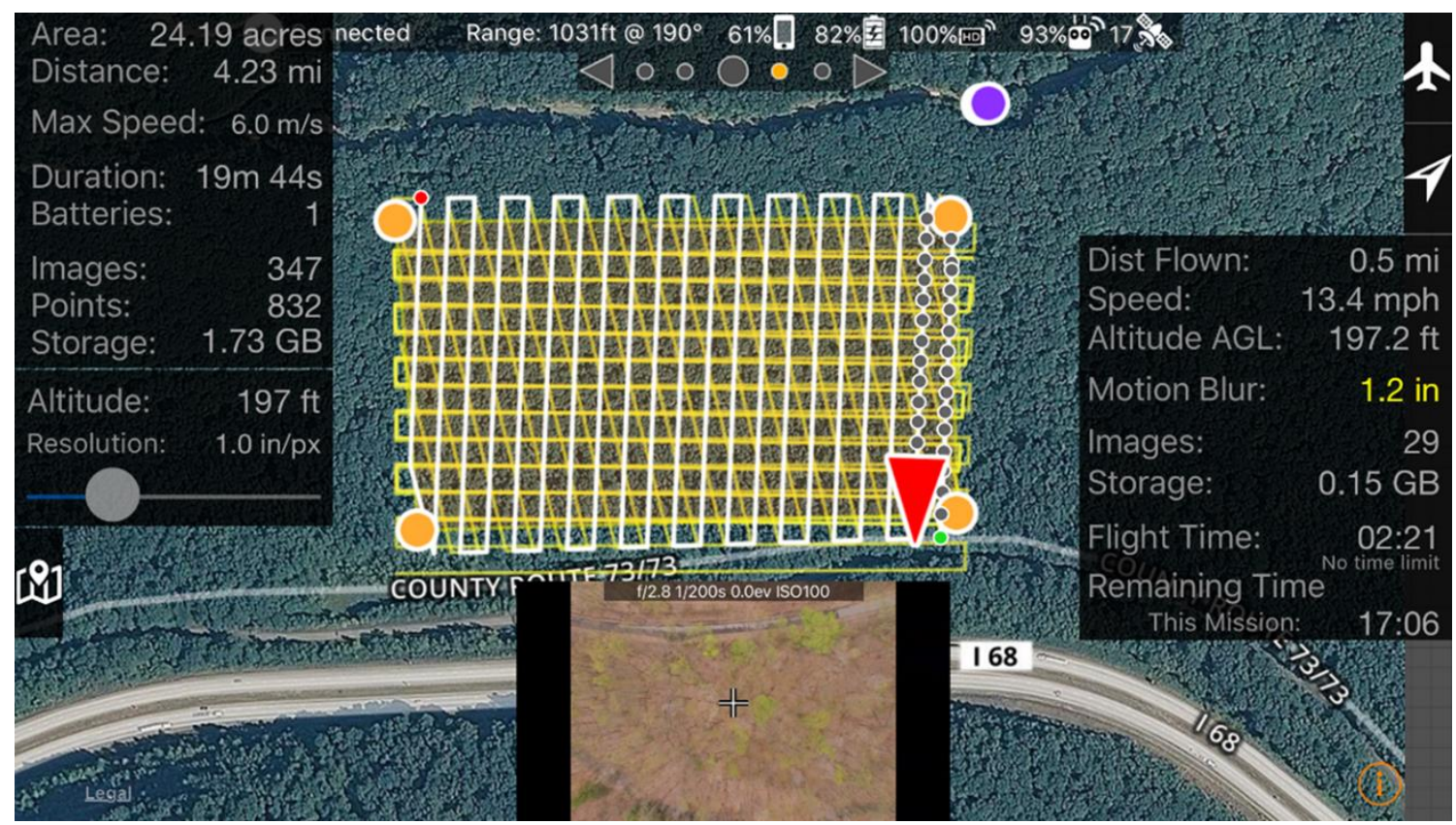

Figure 3. 'Map Pilot' application on-screen display while UAV is in flight. Still images are shown in display in bottom center of screen. UAV location and flight direction represented by red triangle, orange circles represent corners of area of interest and grey circle represent locations of images that have already been acquired. 


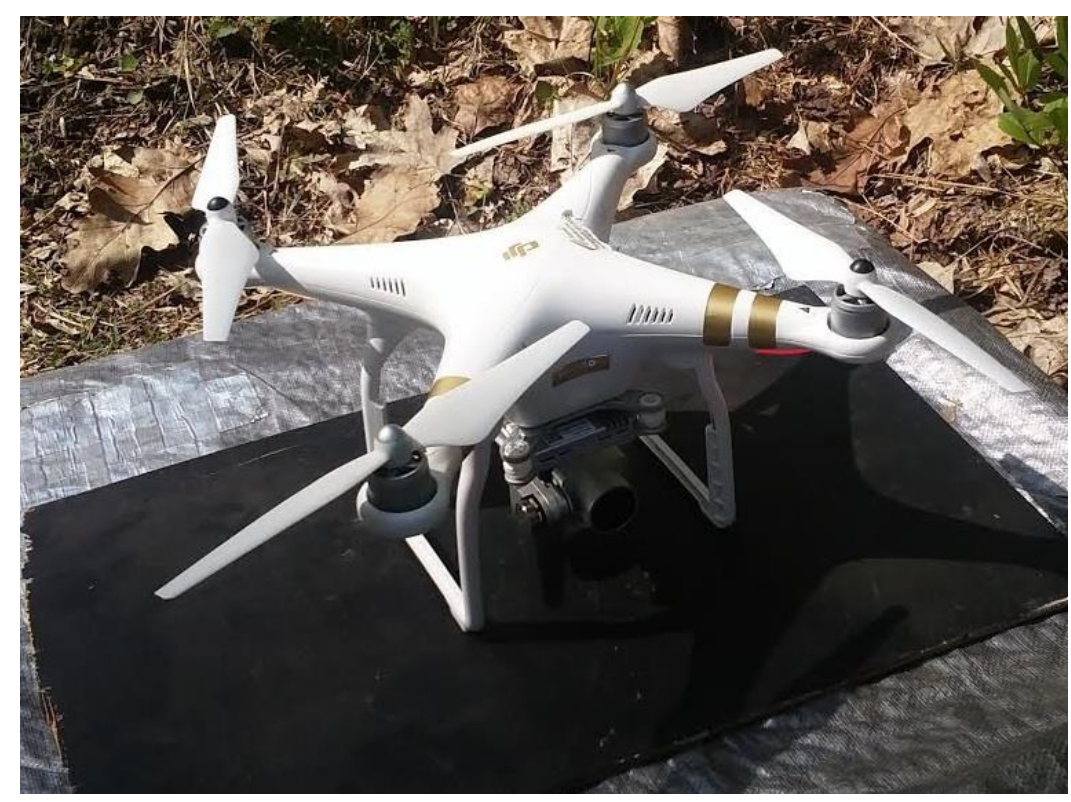

Figure 4. DJI Phantom 3 Professional on homemade landing pad.

Imagery datasets for both seasons were only completed for two sites. Some imagery and GCPs were installed for the other three sites but were not entirely completed due to difficulties with terrain and access. HLO summer imagery was primarily collected on July $26^{\text {th }}$ but some additional images from earlier test flights were used where there were missing data. The fall imagery for the HLO was collected on both October 22 and 25 and were combined in the processing software. The summer imagery for HL3 was collected primarily on August 11 with a few images used from the flights on August 5 . The HL3 early fall imagery was collected on October 19 and the late fall imagery was collected on November 1 . It was the aim for the fall imagery to be collected at the height of fall color change to detect the greatest amount of difference in tree crown colors and extent which was believed to aid in the segmentation process. Two flights were taken for each batch of imagery. One flight was performed in an east-west oriented grid over the area of interest the second was a north-south grid (Figure 5). This resulted in end and side lap of approximately $85 \%$. This significant overlap was needed to ensure there were no gaps in the final mosaics due to the low flying altitude of the UAS during this data collection process (Figure 6). 
East-West

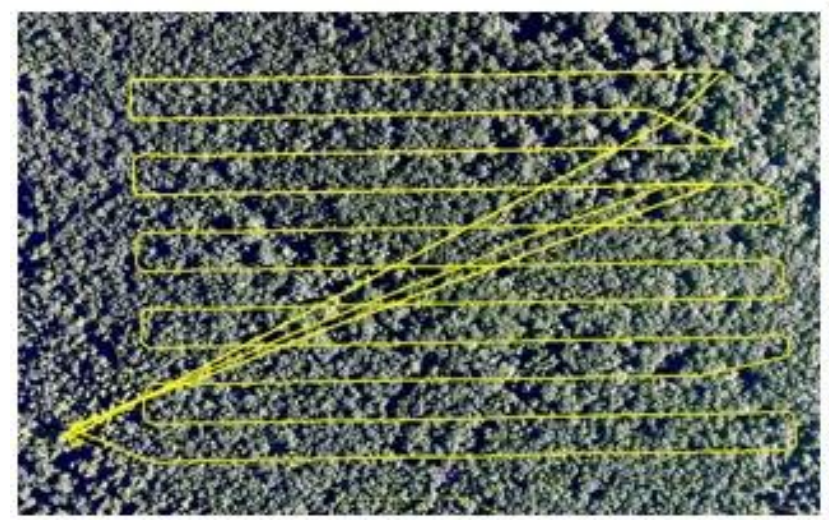

North-South

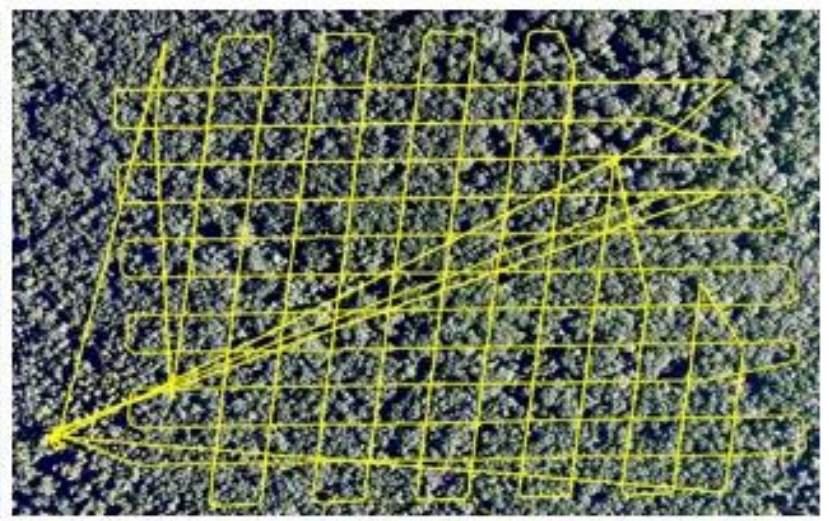

Figure 5. Orientation of UAV flight paths covering the area of interest. The diagonal lines result from when error in the flight occurred; likely exhausted battery. The UAV returns "home", the batteries are replaced and the UAV returns to where it last collected data.

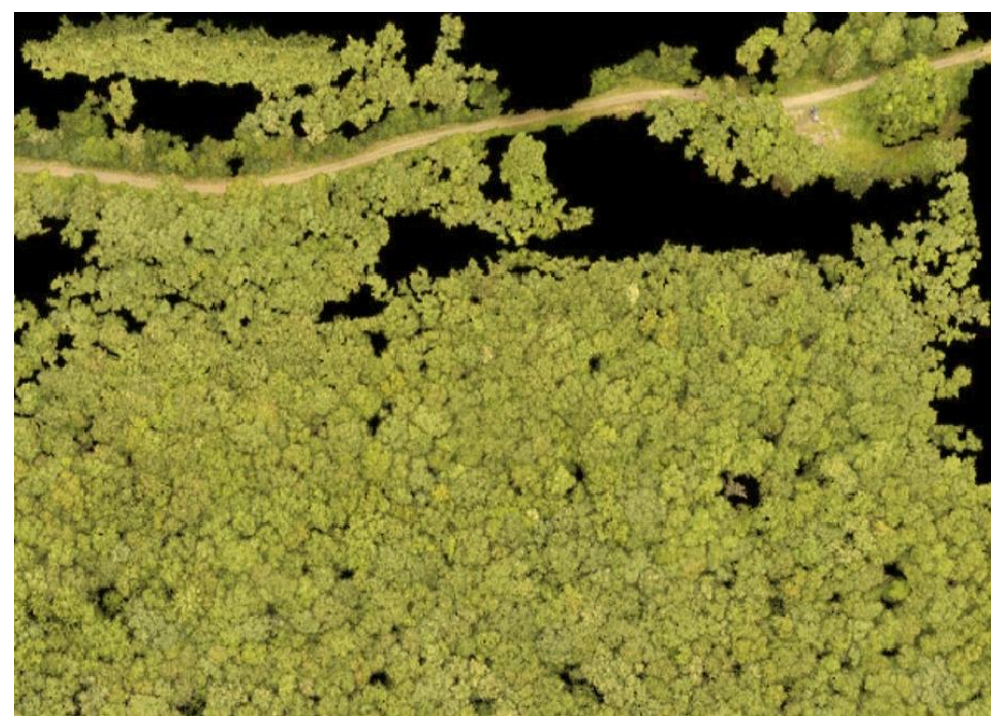

Figure 6. Example of holes in a mosaic draft from the WVU research forest. The black areas occur where areas have insufficient data to complete the mosaic.

Target altitude for all flights was 250 feet above ground level or lower. This was maintained by the feature 'Terrain Aware' in the Map Pilot application. Flights were conducted at the lowest flight altitude possible to get the clearest view of the tree crowns, but this had to be balanced with the risk of losing the drone in the canopy due to changes in topography and the added processing time of a greater number of images from a lower flying altitude. Overcast, but not rainy, days were targeted to produce the most consistency in image collection. Overcast situations have reduced shadows, and when flights took a greater amount of time due to wind or other factors, the lighting scheme would not change as 
drastically during the flight. Flight speed ranged from 5-10 MPH. This variability was primarily caused by changes in wind direction and speeds. Images were recorded every three seconds while the device was in flight. One day was typically necessary to cover each research area. The optimal light window for performing these flights was between $10: 30$ am and $2 \mathrm{pm}$ to reduce shadows. This study was able to accomplish the collection of imagery in one directional (east-west or north-south) flight path for areas of interest no greater than 80 acres in typically one hour. Changeover time and the second direction flight path consume the rest of this important time frame. These flight times are greatly affected by wind speeds.

\section{Ground Control and Imagery Processing}

The limitations for installing GCPs were time, funds, and difficulty of landscape throughout the five research sites. The dense, nearly continuous canopy proved difficult to find gaps and usable sites for ground control in the interior of the forest. An open field to the southeast of HLO was utilized for ground control, as well as County Route 73/73 and Goodspeed Road which bounded the site to the south and north, respectively. The HLO site did not quite extend northward far enough to intersect Goodspeed Road, but a larger swath of land was flown to ensure proper coverage and capture of known landforms for easier ground control as well as to ensure proper coverage. The HL3 site contained distinct features like a gas pipeline right-of-way and a field, as well as a few large single-tree gaps to allow for proper dispersion of ground control throughout this site (Figure 7). The number of ground control points that were withheld for analysis to be used as check points for error calculation within Agisoft was determined by the total number of ground control points collected. 

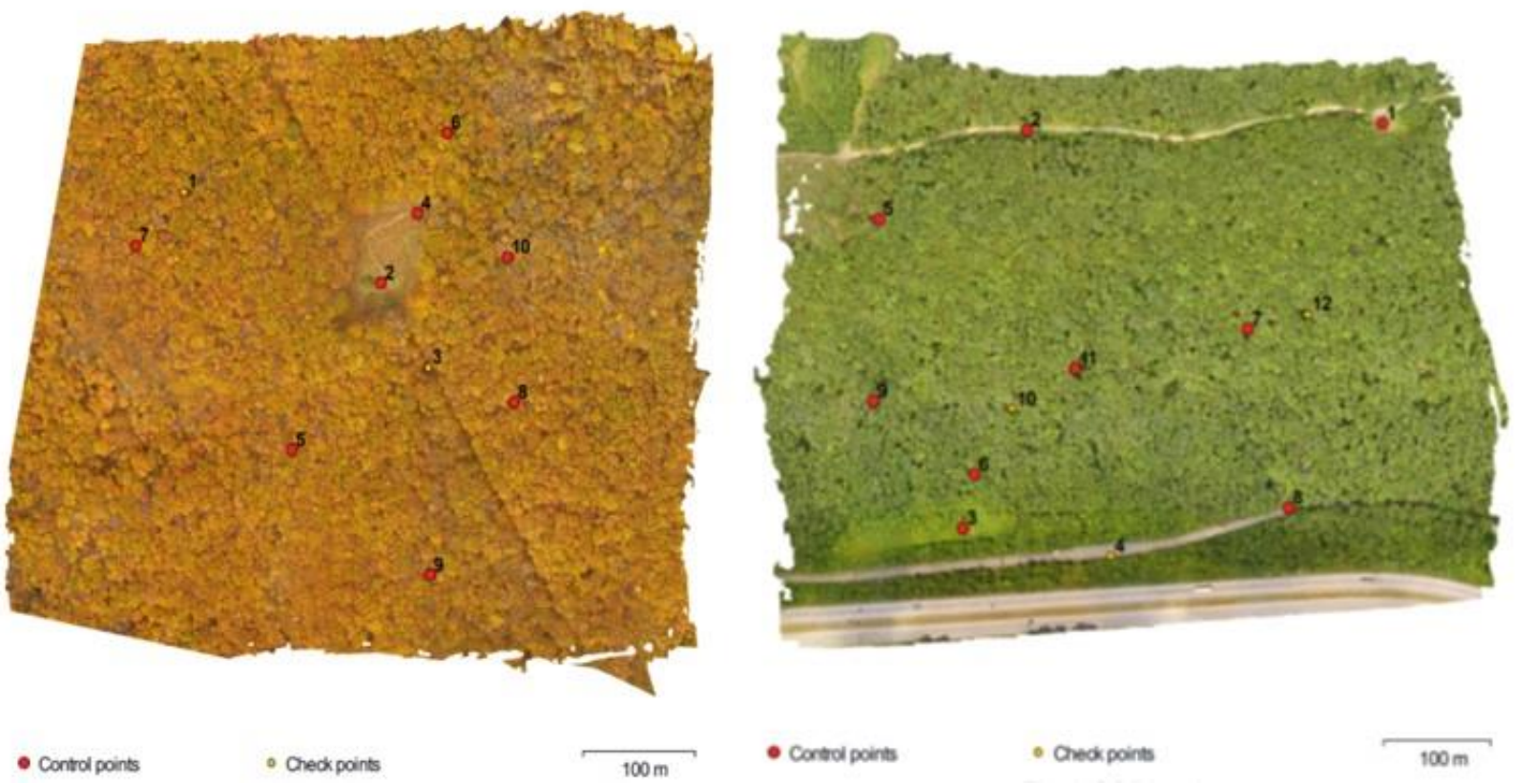

- Contral points

- Ched points

$100 \mathrm{~m}$

$100 \mathrm{~m}$

Figure 7. Distribution of ground control points throughout HL3 (left) and HLO (right). These ground control points remained as permanent locations for use in all seasons of imagery collection.

Each ground control point consisted of a $4 \mathrm{ft}^{2}$ plywood target. Each target was painted white and black for contrast. Targets were meant to be seen in the imagery when the drone flew over so contrast was essential. Larger targets would have been difficult to efficiently place in the interior of the forest. Once established, very accurate (average vertical and horizontal accuracy of two $\mathrm{cm}$ ) GPS coordinates were taken using an iGage X900S-OPUS GNSS static receiver at a standardized height of two meters above ground level (Figure 8). At each GCP the GPS locations were recorded at each point for no less than 121 minutes to ensure proper readings. 


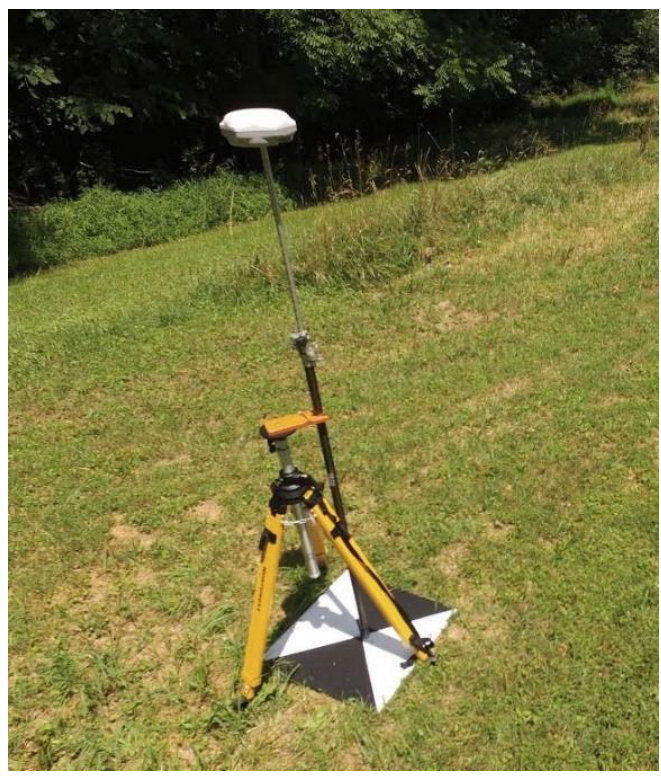

Figure 8. iGage X900S-OPUS GNSS static GPS receiver and $4 \mathrm{ft}^{2}$ black and white plywood target deployed at ground control point location. The static receiver was moved to each GCP location while the targets remained for visibility in aerial imagery.

Imagery was processed using Agisoft Photoscan Professional Version 1.2.6 (Agisoft LLC., St.

Petersburgh, Russia) using a Windows 64-bit device with Intel Xeon CPU E3-1271 v3 at $3.60 \mathrm{GHz}$ and 32 GB of RAM. Images and ground control points were loaded into the software interface to create both the digital structure model (DSM) and the 3-D polygonal mesh (mesh). Both represent the surface of the object of interest based on the dense point cloud. The dense point cloud was processed on medium quality. The mesh was then used to create the orthomosaic. It is important to note that it was necessary for both the LiDAR and the SFM to be processed in the same height projection and for the height metric (ellipsoidal or orthometric) to be consistent to produce accurate and representative heights. In this study, both were processed using orthometric heights. The software identified features in these images and identified each of the images that these features exist in for better referencing. These features are called tie points.

\section{Automated Crown Segmentation and Spatial Measurements}

Segmentation procedures were performed in Trimble eCognition Developer object based image analysis software. Three segmentations were performed for HLO using combinations of the seasonal 
flights. All three were performed by the multi-resolution segmentation tool in the software interface.

The products of this process were ESRI shapefiles of the segmented tree crowns using the summer only imagery, fall only imagery and a combination of the two. Once segmented, the crown area $\left(\mathrm{ft}^{2}\right)$ was calculated in ArcMap.

A normalized digital structure model (nDSM) was produced for both HLO and the HL3 sites. This was developed by subtracting LiDAR ground level from the SFM point cloud from the UAS imagery with the Raster Calculator function in ESRI ArcMap 10.3. The SfM point cloud was rasterized as a DSM which contained an average pixel size of $1.06 \mathrm{~cm}$ across all imagery acquisitions. The LiDAR data, filtered to display just the final ground return, was a $3.28 \mathrm{ft}$ DEM produced by the West Virginia Department of Environmental Protection's Technical Applications and GIS Unit (TAGIS) in 2013 (Figure 9).
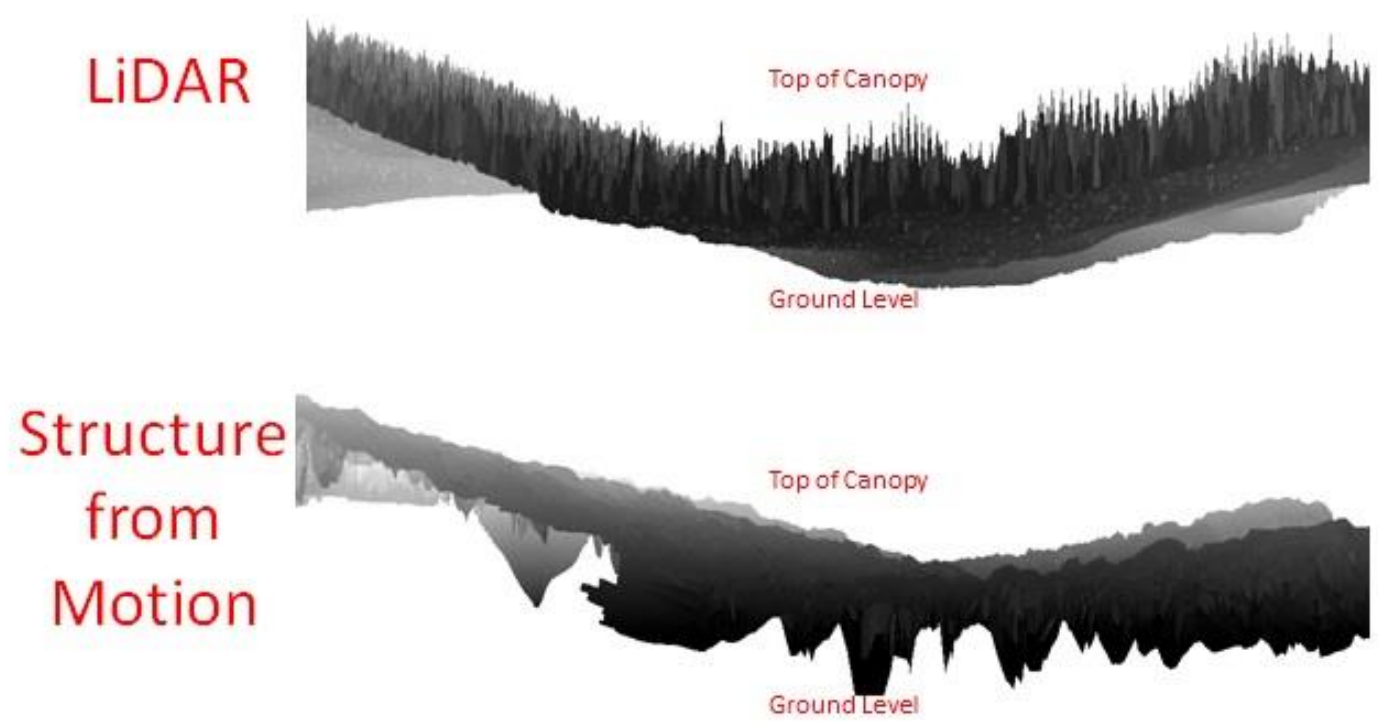

Figure 9. Data from West Virginia University HLO site displaying the distribution of ground points from the LiDAR data collection while the SfM model lacks completeness in coverage of the ground. Structure from Motion point data that penetrated the forest canopy was seldom and very few reached ground level. This image depicts the importance of using LiDAR for ground level data.

The nDSM was then added as a fourth band, along with red, green and blue, to each the summer and fall imagery before the segmentation was performed for HLO. An nDSM was created for each of the three imagery sets (summer, early fall and late fall) for HL3 to examine whether it would be 
beneficial to utilize the height model from each imagery collection or to select one that is most representative of the area as was done with the HLO. These nDSMs, both for HLO and HL3 sites, were added as additional bands to each of the associated images. Images were then stacked to produce composite images in Hexagon Geospatial's Erdas Imagine remote sensing application, creating a seven band image for HLO and a 12 band image for HL3. HLO and HL3 images were then inputted into eCognition and individually analyzed using parameters specific to the dataset (Tables 1).

Table 1. Optimal settings and for each of the composite images for multi-resolution segmentation processing in HLO. The bands are as follows: red, green and blue from the summer mosaic are represented as bands 1,2 and 3 . Red, green and blue bands from the fall mosaic are represented as bands 4,5 and 6 . The $7^{\text {th }}$ band is the $\mathrm{nDSM}$.

\begin{tabular}{cccc}
\hline \multicolumn{4}{c}{ Band Weights } \\
\hline \hline Bands & Summer & Fall & Summer+Fall \\
\hline $\mathbf{1}$ & 3 & - & 4 \\
$\mathbf{2}$ & 1 & - & 1 \\
$\mathbf{3}$ & 1 & - & 1 \\
$\mathbf{4}$ & - & 3 & 3 \\
$\mathbf{5}$ & - & 1 & 1 \\
$\mathbf{6}$ & - & 1 & 1 \\
$\mathbf{7}$ & 5 & 5 & 5 \\
\hline \hline \multicolumn{4}{c}{ Multi-Resolution Segmentation Parameters } \\
\hline Scale & 210 & 250 & 260 \\
Shape & 0.4 & 0.4 & 0.4 \\
Compactness & 0.9 & 0.9 & 0.9 \\
\hline \hline
\end{tabular}

The values for the multi-resolution segmentation parameters and band weights were developed using an iterative process on a subset of each batch of imagery. The tested optimum settings were chosen for each dataset. This proved to be a difficult task for the full composite HL3 segmentation due to the great number of weights and parameter setting possibilities (Table 2). After these parameters were established, they were then applied to the entire image for the final segmentation of each image.

The scale parameter seemed to have the greatest effect on the segmentation results. The lower the scale parameter, the greater number of segmentation objects were created. Finding the balance that captured primarily individual tree crown objects was the focus of the evaluation of the optimum 
parameter settings. The scale parameter is an arbitrary parameter within eCognition that defines the size and number of objects created. There is no range for scale values. The shape parameter ranges from 0-0.9. The higher the value for this parameter, the more consideration the shape of objects is given when performing the segmentation. The compactness parameter defines the weight of the object compactness. This parameter is scaled from 0-0.9. The higher the number, the more compact the objects will be and the lower the number the more abstract and stringy the objects will appear.

Table 2. Optimal eCognition settings used for each of the multi-resolution segmentations produced for site HL3. The bands are as follows: 1-3 are red, green and blue bands from the summer mosaic; 5-7 are red, green and blue bands from the early fall mosaic; 9-11 are red, green and blue bands from the late fall mosaic and 4, 8 and 12 are bands containing the nDSM for summer, early fall and late fall respectively.

\begin{tabular}{|c|c|c|c|c|}
\hline \multicolumn{5}{|c|}{ Band Weights } \\
\hline Bands & Summer & Early Fall & Late Fall & $\begin{array}{c}\text { Summer+ } \\
\text { Early Fall+ } \\
\text { Late Fall }\end{array}$ \\
\hline 1 & 2 & 0 & 0 & 1 \\
\hline 2 & 1 & 0 & 0 & 1 \\
\hline 3 & 1 & 0 & 0 & 1 \\
\hline 4 & 10 & 0 & 0 & 1 \\
\hline 5 & 0 & 2 & 0 & 1 \\
\hline 6 & 0 & 1 & 0 & 1 \\
\hline 7 & 0 & 1 & 0 & 1 \\
\hline 8 & 0 & 10 & 0 & 1 \\
\hline 9 & 0 & 0 & 2 & 1 \\
\hline 10 & 0 & 0 & 1 & 1 \\
\hline 11 & 0 & 0 & 1 & 1 \\
\hline 12 & 0 & 0 & 10 & 10 \\
\hline \multicolumn{5}{|c|}{ Multi-Resolution Segmentation Parameters } \\
\hline Scale & 330 & 260 & 290 & 260 \\
\hline Shape & 0.6 & 0.6 & 0.7 & 0.6 \\
\hline Compactness & 0.9 & 0.9 & 0.9 & 0.9 \\
\hline
\end{tabular}

Each of the segmentations were performed in roughly 30 minutes. The nDSM weight was treated as the greatest due to the practice of local maxima segmentation methods for tree crown segmentation (Zawawi et al., 2015). The high points would be established as the highest point of each of the individual tree crowns and the shadows surrounding each one of these tree crowns would be represented by consistently decreasing height values as pixels proceed to the edges of the crown. Also, 
the red bands of most of the images were weighted higher than the green and blue bands due to the observation that contrast in brightness values was greatest in these bands when viewed individually. It was believed that this contrast would give the segmentation the most information to predict tree crown boundaries. The red band in the summer image of HLO provided more contrast than that of the red band of the fall image of HLO, thus was given a higher weight.

Gaps in the tree canopy for HLO were removed from the object list before further processing by selecting all objects with a mean nDSM value less than $61.88 \mathrm{ft}$. This threshold was chosen by being half of the maximum nDSM value of $123.75 \mathrm{ft}$ to target the removal of trees with a crown class of intermediate or suppressed. This resulted in the removal of 116 objects with a grand total of 2,305 objects for the fall and summer composite image. This method also removed 36 objects from the fall imagery and 68 from the summer, resulting in a grand total of 2,574 and 3,715 objects respectively. An attempt to remove gaps and the large field within HL3 was performed by removing all objects with a mean nDSM value less than $55.5 \mathrm{ft}$. Although the mean nDSM value for this site was $128 \mathrm{feet}$, when half of this maximum height was utilized many trees were selected within this site due to the stunted growth of a number of trees in a boulder field in the southwest corner of this site. Adjustments were made (to $55.5 \mathrm{ft}$ ) until the selection excluded canopy trees and targeted gaps.

\section{Field Inventory}

One-tenth acre circular plots were distributed throughout the five research areas on a grid pattern with spacing appropriate to create roughly a 1 ac: 1 plot ratio throughout each of the five areas. A total of 129 field plots were installed. Navigation to all field plots was done using a WAAS-enabled, handheld Garmin eTrex Legend H GPS receiver.

The metrics recorded at each of the field plots were: aspect, tree number, species of each tree, $\mathrm{DBH}$, crown class, total height, merchantable height (to a 10 in top or other form of stoppage), and azimuth and distance from plot center to each stem. All stems above $4.0 \mathrm{in} \mathrm{DBH}$ were recorded and the 
crown classes that were used were suppressed, intermediate, co-dominant and dominant. Total heights were recorded for all trees that were of co-dominant or dominant crown class or individuals who existed in gaps and would be visible in aerial imagery. Merchantable height was measured on individuals whose DBH was of 12.0 in or greater and was recorded to the nearest quarter log. Standard log measurements of 16 foot lengths were used in this study. Total height was recorded with Laser Technology TruPulse 200 Laser hypsometer and the upperstem limit of merchantable stems was identified using both the TruPulse laser and Laser Technology Criterion RD 1000 laser linked via cable. All trees were marked with unique number identifiers within each plot for revisiting.

\section{Field Crown Measurements}

A subset of plots was chosen to represent the crown verification measurement group. Five plots from each of the five research sites. These individuals from the five plots were used to verify the crown area measurements produced from the automated segmentation process as well as in the development of the allometric relationship of tree crown area and DBH. A total of 218 tree crowns were measured throughout this process.

The calculation of tree crown area was done by dissecting the tree crown, on the ground, into six irregular triangles. The sum of the area of all six triangles would result in the area of the entire tree crown. The first step in the calculation of tree crown area was creating vertices at the drip line every 45 degrees from the stem of the tree, totaling 8 vertices per crown (Figure 10). Field observers utilized a clinometer to ensure that measurements were taken directly below the dripline. 


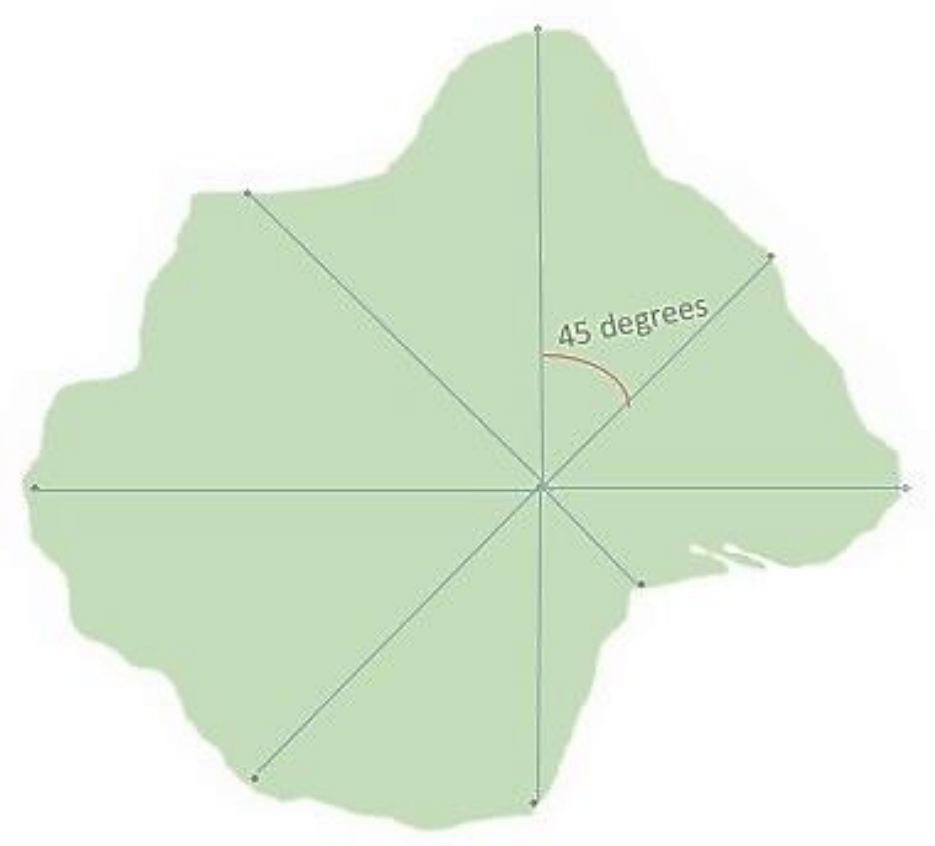

Figure 10. Vertices at the drip line of the tree crown every 45 degrees around the stem of the tree. North is in the direction of the top of the page.

Measurements were taken starting from the vertex at the drip line, 0 degrees north of the stem to each of the succeeding vertices. These measurements, recorded to the nearest $0.1 \mathrm{ft}$, created two legs of the irregular triangles for each of the six triangles of interest. The final leg was created by measuring between each vertex beyond 0 degrees north. For example, measurements were taken from the 45 degree vertex and the 90 degree vertex, the 90 degree vertex and the 135 degree vertex and so on. These measurements resulted in six triangles (Figure 11). 


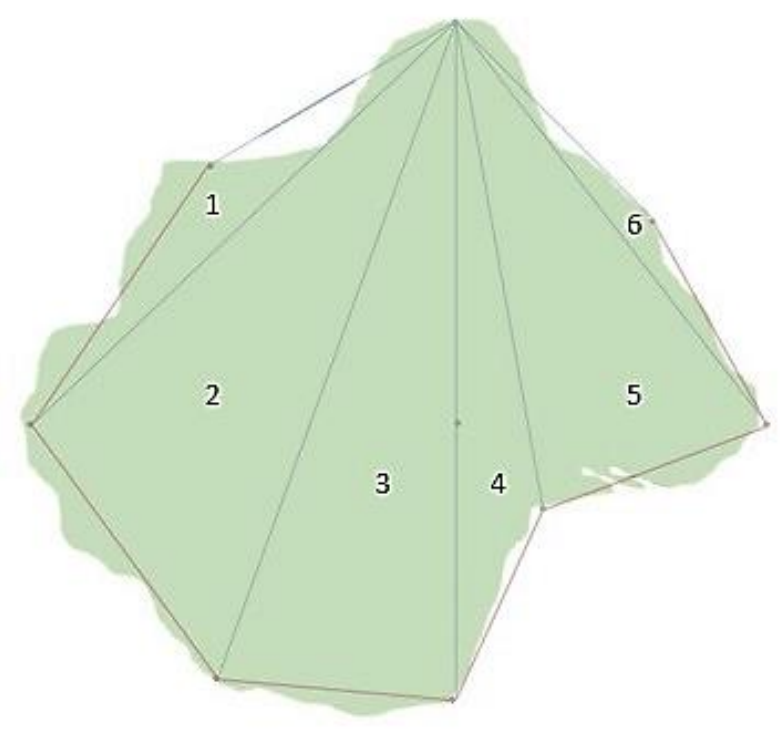

Figure 11. The six triangles produced from field measurements to calculate area of irregular octagon. Blue lines represent measurements to vertices from 0 degrees north and red lines represent measurements between vertices beyond 0 degrees north. Top of page represents north.

Measurements were also taken from the tree stem every 90 degrees to the drip line of the tree crown (Figure 12). These measurements were used to calculate a mean crown radius (MCR), treating the tree crown as a circle to create a tree crown area. The comparison between this MCR method and the adapted Heron's method was performed.

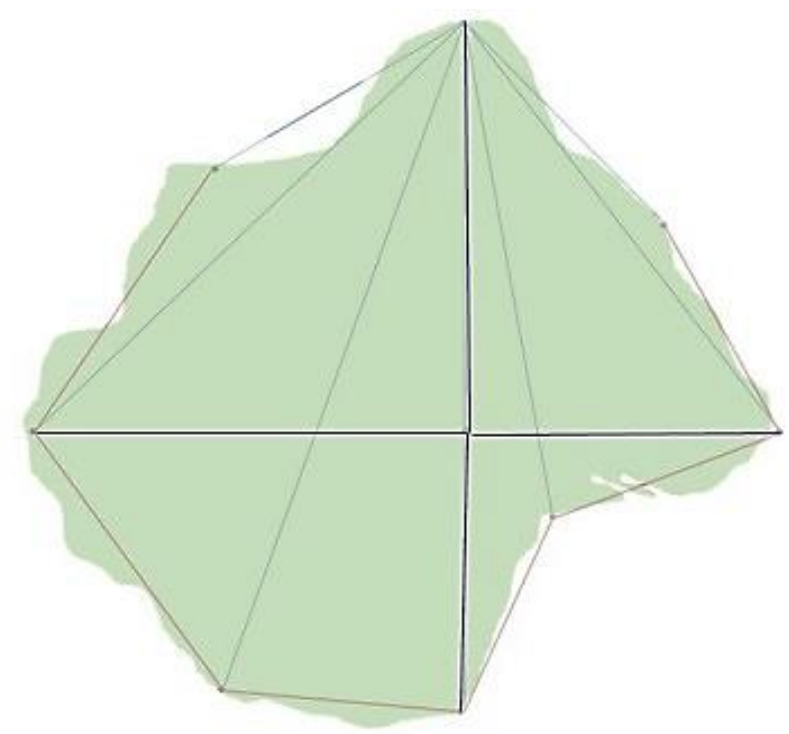

Figure 12. Cardinal direction measurements from tree stem to drip line for calculation of tree crown area using the method of tree crown radius. Top of page represents north. 
The field data was synthesized using Heron's formula (Stubberud \& Kramer, 2009):

$$
\text { Triangle Area }=\sqrt{\mathrm{s}(\mathrm{s}-\mathrm{a})(\mathrm{s}-\mathrm{b})(\mathrm{s}-\mathrm{c})}
$$

where: $a, b$ and $c$ are all vertices of one of the six triangles and

$$
s=\frac{1}{2}(a+b+c)
$$

The above equation calculates the area of one of the six equations. The total tree crown area was calculated by taking the sum of all six triangle area calculations. The mean of the four radius measurements was calculated for each tree crown and the tree crown area using this method was calculated by using the equation for the area of a circle.

\section{Boardfoot Volume Calculations}

Field Volume

All inventory data, field and drone derived, was processed in EZ CRUZ Version AR 4.03 inventory software package. The inputs into this software include: individual identification number, plot number, species, DBH, product, merchantable height in logs, and Girard form class. The plot size was set to $1 / 10^{\text {th }}$ acre for field data. The log rule used for both field and drone derived volumes was International 1/4".

Product numbers were either 1 for sawtimber or 2 for pulpwood. This distinction was created at the 12.0 DBH cut off. Above this cutoff, individuals were classified with a product of sawtimber and below this threshold they were classified as pulpwood. The merchantable height was rounded down to the nearest quarter log. Standard sixteen foot full logs were used for this inventory. The Girard form class that was set automatically by the software for the red oak species was 78 . The data was processed and output into a Microsoft Excel format.

\section{UAS Derived Volume}

Without species classification data, volume numbers would need to assume a form class 78 for all observations. The species that was chosen to represent all observations was northern red oak. This is 
due to northern red oak's prevalence across the site and it is understood to be indicative of quality sites throughout the WVU Research Forest.

A nonlinear model was developed in the program Curve Expert to predict stem DBH from field measured crown area. This model was developed using field DBH and ground measured tree crown areas throughout all five field sites for this study. The model developed and utilized through this process was:

$$
\mathrm{DBH}=8.09844 *\left(\mathrm{C}^{0.5}\right)^{0.26566}
$$

Where $\mathrm{C}=$ crown area in $\mathrm{ft}^{2}$ and $\mathrm{DBH}$ is measured in inches.

The DBH derived from the above equation was then inputted into a model to predict merchantable height from DBH (Brook \& Wiant, 2006). Such as for the field data, northern red oak was the assumed species and the equation that was utilized is as follows:

$$
\text { MHT }=\operatorname{Exp}\left\{4.0269+-8.390\left(\frac{1}{\mathrm{DBH}}\right)\right\}
$$

Where MHT is represented in feet and DBH in inches.

The data was inputted into EZ CRUZ to calculate stand statistics.

\section{Evaluation of Accuracy and Statistical Review}

For much of this study, qualitative analysis and evaluation were the primary measure of success. Visual evaluation of segmentation quality of fit was performed for all segmentation results. Each of the results were displayed on their associated orthomosaic. For the HLO composite segmentation, summer imagery was used. For the HL3 composite segmentation, a combination of early fall and summer imagery was used. A random number generator was used to select 30 segmented objects. These 30 tree crowns would be turned on and evaluated for their goodness of fit to the targeted tree crown in the imagery using a chi-squared test of homogeneity. If the random number represented a gap polygon, a new number would be generated until a polygon did not obviously align with a gap. For each of these segmentations, the number of correctly delineated tree crowns was recorded. A correctly segmented 
tree crown was considered a polygon that reasonably defined the full extent of an individual tree crown with minimal under or over segmentation (Figure 13). The optical threshold for a correctly segmented tree crown was $80 \%$ of the tree crown area correctly segmented.
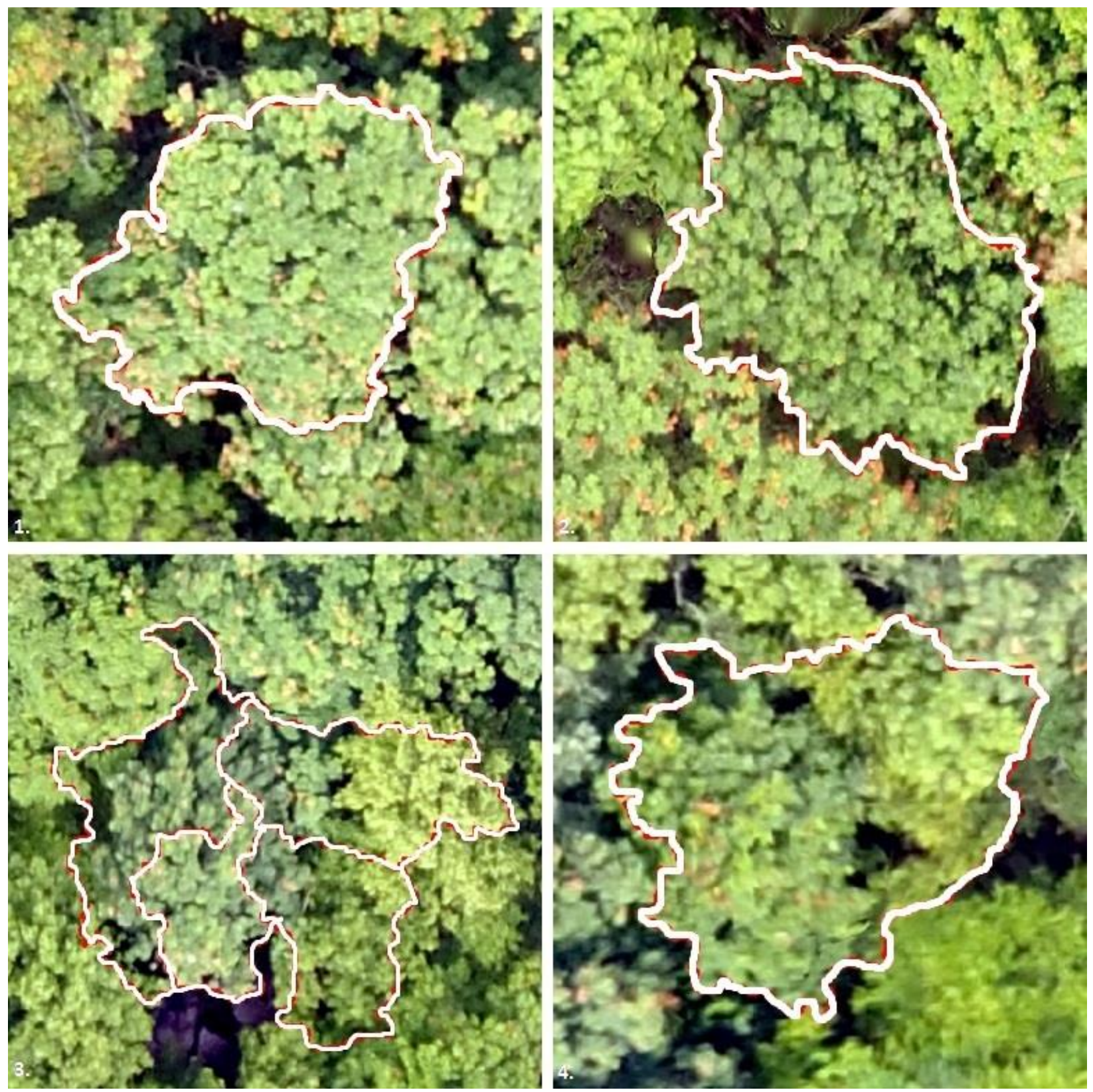

Figure 13. Counterclockwise from the upper left: (1) Correctly segmented tree crown that would be considered a success; (2) correctly segmented tree crown that would considered a success; (3) Over segmented tree crown that would be considered a failure; (4) Under segmented tree crown that would considered a failure. 
Segmentation of gaps was evaluated in a similar fashion between seasonal imagery. Gaps that were removed before volume calculations were evaluated optically on goodness of fit and random objects were selected to represent a reference point for a further analysis. The gap nearest to the random object was considered either successfully segmented or not. An $80 \%$ optical threshold of fit was used to determine successful segmentation. If the random object selected was a gap and it was $80 \%$ segmented correctly, then it was considered successfully segmented.

Static GPS coordinates were collected for the plot centers of three of the field plots in HLO at which field crown measurements were also collected. These GPS measurements provided a highly accurate measure of these locations in space. The distance from plot center as well as the azimuth recorded through the field inventory were used to create a stem map of each of the three plots. These stem maps were used to visually understand where the location of each stem in these plots should exist in space and to allow the user a measure of how well each tree crown within these plots was segmented. Centered on each plot, a $1 / 10^{\text {th }}$ acre circular plot was placed in ArcMap. Within each plot, crowns were heads-up digitized. Field crown measurements were used to verify delineated tree crown area measurements.

The goodness of fit measures for each of the tree crown segmentations and gap fit were statistically analyzed through a chi-squared test of homogeneity in RStudio, open-source integrated development environment. Evaluation of field and heads-up digitized tree crown areas for the three $1 / 10^{\text {th }}$ acre plots was also done in RStudio by way of Welch's two-sample t-test. A statistical evaluation of field measured merchantable heights and Brooks \& Wiant (2006) derived merchantable heights was performed using a Welch's two-sample t-test. This comparison was done on field measured merchantable heights for trees in $\mathrm{HLO}$ and $\mathrm{HL} 3$ and merchantable heights were also estimated for these same individuals using the measured DBH from field data collection. The alpha value for all statistical analyses was 0.05 . 


\section{Results}

The initial results of this project revolve heavily around the evaluation of the quality of the UAS imagery (Table 3). The RMSE was calculated by the Agisoft software and is an estimate of error utilizing the inputted GCP check points. This error value is the difference between measured GPS location and software estimated GPS location for the check points. Flight time resulted in an approximate four hours per site per day which constitutes a full day for purposes of aerial imagery acquisition.

Table 3. Evaluation of imagery from all sites and seasons available. The processing time is the sum of all processing times necessary for all stages of the image processing.

\begin{tabular}{l|cc|ccc}
\multicolumn{1}{c|}{ Site } & \multicolumn{2}{c|}{ HLO } & \multicolumn{3}{c}{ HL3 } \\
\hline \hline \multicolumn{1}{c|}{ Season } & Summer & Fall & Summer & Early Fall & Late Fall \\
\hline Area Flown (ac) & 79 & 76 & 64 & 67 & 71 \\
Processing Time (hrs/ac) & 2.7 & 1.4 & 3.8 & 16.8 & 5.1 \\
Total Processing Time (hrs) & 29 & 51 & 17 & 4.0 & 14 \\
Number of images & 1673 & 2046 & 1496 & 778 & 1571 \\
RMSE (ft) & 16.90 & 15.00 & 36.98 & 31.10 & 1.61 \\
Number of points (millions) & 57.9 & 49.0 & 56.7 & 49.5 & 56.0 \\
Number of GCPs & 12 & 12 & 9 & 8 & 10 \\
Acres per GCP & 6.6 & 6.3 & 7.1 & 8.4 & 7.2 \\
Resolution (in) & 1.19 & 1.15 & 0.94 & 0.98 & 0.98 \\
Flying Altitude (ft) & 266 & 253 & 203 & 223 & 226 \\
Tie points (millions) & 3.75 & 2.27 & 2.24 & 0.95 & 0.84 \\
\hline
\end{tabular}

The area flown is greater than the site area due to the significant amount of overlap needed to ensure proper coverage. It is important to note that the early fall imagery only used half of the images (north and south flight lines) due to the lighting change throughout the day of acquisition. The HL3 early fall dataset had the fewest number of images and the shortest processing time. The late fall imagery had shorter processing time (82\%) than summer HL3 imagery but greater number of images. The RMSE was the lowest for the late fall imagery. The resolution was the highest for the summer HL3 imagery and also had the lowest flying altitude. The processing time for both of the sets of HLO imagery was far greater than those of the HL3 imagery. Fall imagery datasets had 13\% lower ground control RMSE than summer 
imagery for $\mathrm{HLO}$ and $18 \%$ lower error for early fall compared to summer imagery in HL3. Late Fall RMSE was 23 times lower than summer imagery RMSE for HL3.

The quality of segmentations when evaluated visually was unsatisfactory compared to past research. The least successful segmentations were the summer, early fall and composite images for HL3 with only a $17 \%$ success rate. Although the fall and summer composite image for HLO produced the greatest number of successes at $43 \%$, there is no statistical difference between any of the segmentation goodness of fit evaluations. Similarly, there were no statistical differences among temporal UAS aerial imagery for correctly segmenting tree crowns (Table 4).

Table 4. Segmentation results for all imagery and combinations. Chi-squared tests of homogeneity were performed on successes between segmentations of each site as well as between both sites.

\begin{tabular}{cccccc|c} 
Site & Segmentation & Successes & Failures & Success Rate & $\begin{array}{c}\text { chi-squared } \\
\text { p-value }\end{array}$ & $\begin{array}{c}\text { chi-squared } \\
\text { p-value }\end{array}$ \\
\hline \hline \multirow{3}{*}{ HLO } & Summer & 8 & 22 & $27 \%$ & & \\
& Fall & 7 & 23 & $23 \%$ & 0.20 & \\
& Stacked Image & 13 & 17 & $43 \%$ & & \\
\hline \multirow{4}{*}{ HL3 } & Summer & 5 & 25 & $17 \%$ & & \multirow{2}{*}{0.18} \\
& Early Fall & 5 & 25 & $17 \%$ & \multirow{2}{*}{0.69} & \\
& Late Fall & 8 & 22 & $27 \%$ & & \\
& Stacked Image & 5 & 25 & $17 \%$ & & \\
\hline
\end{tabular}

Average crown area from field data was $385 \mathrm{ft}^{2}$ and the average crown area for heads-up digitized crowns was $352 \mathrm{ft}^{2}$ in three plots in HLO, which was not a significant difference $(p=0.62)$. This verified the field crown measurements that were used in the DBH relationship equation. The relationship between $\mathrm{DBH}$ and crown area derived from field data had an $\mathrm{R}^{2}$ value of 0.22 (Figure 14).

There was a significant difference between field measured and predicted merchantable height values, using Brooks and Wiant (2006), in both HLO and HL3 ( $p=0.003)$. The volume numbers were inconsistent with large variation between segmentations and field data (Table 5). 


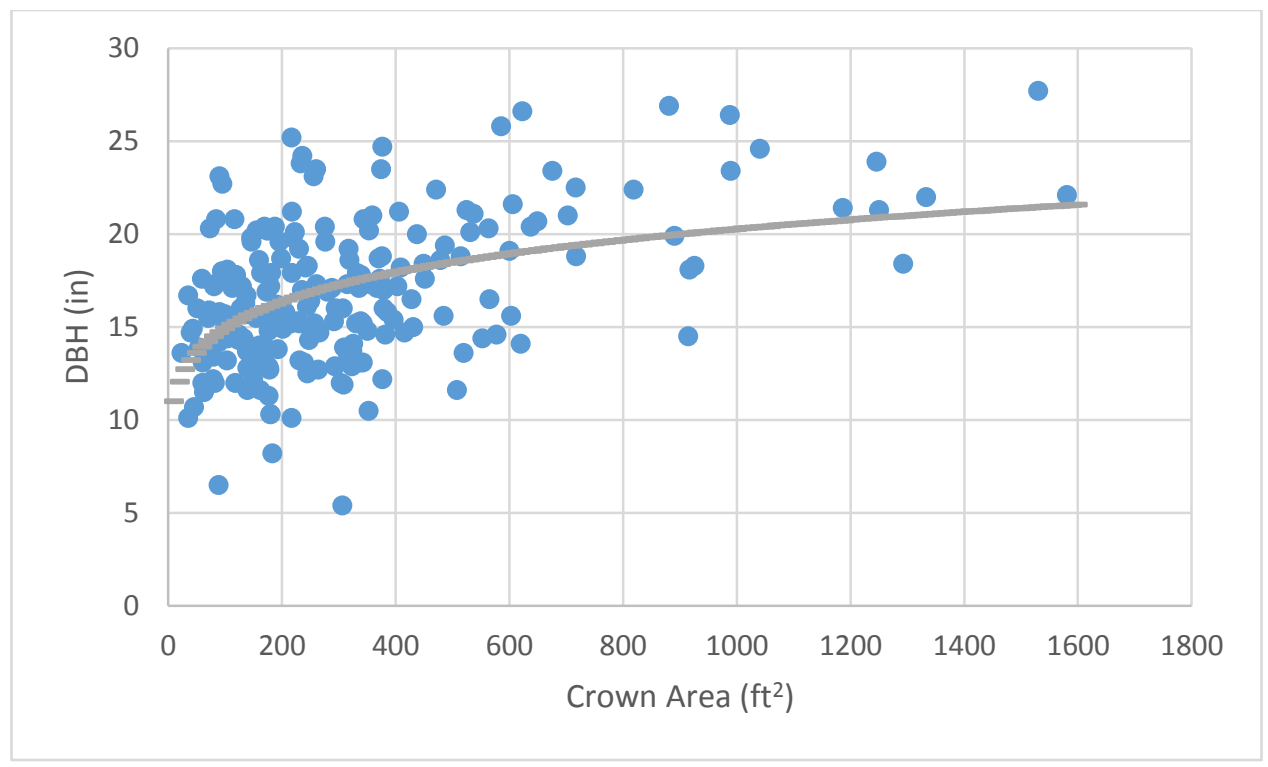

Figure 14. Blue values represent observed crown area and DBH measurements. Overlaid in grey is the predictive equation results for $\mathrm{DBH}$ from crown area.

Table 5. The EZ CRUZ derived volume and other forest metrics for all of the segmentations compared with the field data for each of these sites. Field estimates are shown with a 95\% confidence interval.

\begin{tabular}{llccccc} 
& & & & & \multicolumn{3}{c}{$\begin{array}{c}\text { AVG } \\
\text { DBH }\end{array}$} & $\begin{array}{c}\text { AVG MHT } \\
\text { (ft) }\end{array}$ \\
\hline \hline \multirow{2}{*}{ Season } & MBeld (4" DBH and above) & $18.0 \pm 3.0$ & $168.6 \pm 7.9$ & $155.8 \pm 15.2$ & 11.8 & 36.7 \\
& Field (12" DBH and above) & $18.0 \pm 3.0$ & $81.4 \pm 7.9$ & $127.9 \pm 15.2$ & 16.8 & 36.7 \\
& Fall/Summer & 25.2 & 120.4 & 193.1 & 17.1 & 34.1 \\
& Fall & 27.3 & 134.5 & 211.0 & 17.0 & 33.9 \\
& Summer & 34.1 & 194.1 & 273.0 & 16.1 & 32.9 \\
\hline \hline & Field (4" DBH and above) & $13.6 \pm 2.7$ & $190.5 \pm 8.8$ & $155.1 \pm 19.6$ & 10.9 & 32.9 \\
& Field (12" DBH and above) & $13.6 \pm 2.7$ & $80.5 \pm 8.8$ & $121.1 \pm 19.6$ & 15.9 & 32.9 \\
HL3 & 28.6 & 148.1 & 223.7 & 16.6 & 33.6 \\
& eFall/IFall/Summer & 32.7 & 180.7 & 259.7 & 16.2 & 33.2 \\
& early Fall & 25.9 & 126.8 & 199.4 & 17.0 & 33.9 \\
& late Fall & 26.6 & 132.2 & 205.6 & 16.9 & 33.8 \\
\hline
\end{tabular}

Due to the crown area diameter relationship, the segmented datasets primarily estimated individual trees with DBH 12 in or greater. The maximum number of trees per acre for any segmented dataset was 2.9 TPA for summer HLO. The segmented datasets underestimate TPA when stems under 12 in are included (with the exception of HLO summer segmentation) but overestimate when stems below 
12 in are removed. Basal area was overestimated in the segmentation datasets regardless of stems less than 12 in DBH are included. Average diameter was within 5\% of the field calculated average dimeter for HLO segmentations except for the summer segmentation and within 6\% for all HL3 segmentations. HLO average MHT had a greater range of data than that of $\mathrm{HL} 3(3.8 \mathrm{ft}$ and $1 \mathrm{ft}$ respectively).

The fall and summer composite image for HLO produced the volume estimate that was closest to the calculated field volume estimate. The fall and summer composite image segmentation produced volume numbers that were $40 \%$ greater than the field data. The greatest difference in HLO volume estimates was from the summer only segmentation derived volume estimates. These estimates were $90 \%$ greater than the field estimates. The volume predictions derived from the segmentations in HL3 were much larger than the field volume estimate. The closest volume estimate was from the late fall only segmentation, which produced volume estimates $91 \%$ greater than the field data. The highest volume estimate for HL3 was the early fall only segmentation with volumes $141 \%$ greater than the field data estimates.

Gaps were identified with higher success than tree crowns regardless of imagery season for both sites. The gaps that were removed before volumetric analysis were evaluated to produce how well each season of imagery uniformly identified gaps as gaps when these objects were queried for removal (Table 6). Each set of imagery was also evaluated on the ease of gap segmentation in general (Table 7).

Table 6. Quality of gap identification within each set of imagery.

\begin{tabular}{llcccc} 
Site & Segmentation & Successes & Failures & Success Rate & $\begin{array}{l}\text { chi-squared } \\
\text { p-value }\end{array}$ \\
\hline \hline \multirow{3}{*}{ HLO } & Summer & 23 & 7 & $77 \%$ & \\
& Fall & 15 & 15 & $50 \%$ & 0.09 \\
& Summer and Fall & 20 & 10 & $67 \%$ & \\
\hline \hline \multirow{4}{*}{ HL3 } & Summer & 10 & 20 & $33 \%$ & \\
& Early Fall & 4 & 26 & $13 \%$ & 0.19 \\
& Late Fall & 6 & 24 & $20 \%$ & \\
& Sum + EFall +LFall & 10 & 20 & $33 \%$ & \\
\hline
\end{tabular}


Table 7. Quality of gap identification across all sets of imagery. The values below were not queried for removal but were identified from all objects in segmentation results.

\begin{tabular}{clcccc} 
Site & Segmentation & Successes & Failures & Success Rate & $\begin{array}{l}\text { chi-squared } \\
\text { p-value }\end{array}$ \\
\hline \hline \multirow{3}{*}{ HLO } & Summer & 24 & 6 & $80 \%$ & \\
& Fall & 19 & 11 & $63 \%$ & 0.36 \\
& Summer and Fall & 21 & 9 & $70 \%$ & \\
\hline \hline \multirow{4}{*}{ HL3 } & Summer & 16 & 14 & $53 \%$ & \\
& Early Fall & 14 & 16 & $47 \%$ & 0.63 \\
& Late Fall & 19 & 11 & $63 \%$ & \\
& Sum + EFall +LFall & 17 & 13 & $57 \%$ & \\
\hline
\end{tabular}

Although HLO summer imagery had the greatest success rate for gap identification (80\%) in both HLO and for all sites as a whole and HL3 early fall had the worst (47\%), there was no significant difference between any of the gap detections. Overall gap identification was on average $37 \%$ greater than tree crown identification for all sites, $40 \%$ better for $\mathrm{HLO}$, and $36 \%$ better for $\mathrm{HL} 3$. Although there was a greater success rate in gap analysis for all sites, there was no statistical significance between temporal UAS data for gap identification. There was only a 7\% average difference between success rates in HLO for gaps queried for removal, while there was 30\% average difference for HL3 gaps queried for removal. This shows a distinct deficiency of the query at representing the gap identification quality of the segmentations for HL3.

\section{Discussion}

This development of a work flow for UAS forest imagery is not an entirely new process (Puliti et al., 2015; Lisein et al., 2015) but the application of these methods to a complex mixed hardwood forest ecosystem is a challenging and rewarding beginning. The discovery of the difficulties in the acquisition of the imagery were of great importance for these settings. Ground control was a laborious task. It was believed that GCPs could be viewed easily throughout each stand. However, in very few instances was a single tree canopy gap sufficient for ground control as these gaps were not large enough for the visual 
identification of the targets when imagery was collected due to the presence of the midstory. It was soon realized that large openings, typically greater than a single tree gap, and visible structures such as rock outcroppings, roads or fields would need to be used for this practice. Through observation, it was essential to utilize at least 121 minutes for the occupation using the iGage X900S-OPUS GNSS static GPS receiver or the risk of GPS coordinates failing to be returned was great.

The collection of imagery in one day was limited to no more than one 79 acre site with proper overlap and coverage. The amount of area that can be flown is greatly limited by the lighting of the day and battery life but the battery capacity for the DJI Phantom 3 Professional is adequate for this application. The type of drone used is also a limit to the area of coverage. An increase in extent would require the UAV to be flown at a higher altitude which would reduce the resolution of the final imagery product. The use of a professional grade UAV, more suitable for larger extents, could also increase the speed at which data could be collected without suffering a decrease in quality. There is an inverse relationship between flight altitude and spatial resolution; the greater the flight altitude the lower the resolution.

At the HL3 site, it was possible to develop imagery with high spatial resolution with only one direction of flight lines (e.g. east-west flight lines) for the early fall. However, this set of imagery produced one of the worst segmentation results as a result of unreliable data from the lack of images. This point cloud had the second fewest number of points, the second fewest number of tie points and the least amount of ground control points which produced a less reliable product for measurements. The overlap of $85 \%$ is supported in literature as a means to avoid gaps in data and to ensure that the best coverage of all sides of tree crowns is established (Haala, 2013).

In many cases the imagery processing with Agisoft was the most time consuming step in the procedure. Dense point cloud construction, which all later processes within Agisoft require, was performed with medium quality. The difference between products produced on medium and high 
quality was negligible but was actually better on medium accuracy with a ground resolution and ground control RMSE of 1.19 in and $16.90 \mathrm{ft}$ on medium accuracy and 1.24 in and $16.93 \mathrm{ft}$ on high accuracy respectively. But, the medium processing time was far less ( 29 hours) than that of the high quality (164 hours). Processing was initially performed on high accuracy but negligible differences in accuracy and high processing times determined that medium accuracy was a better fit. These same tradeoffs were also selected as the optimal settings through trial and error in Puliti et al. (2015). There are few methods beyond improving the hardware of the machine used for processing to reduce this time needed to produce fully rectified orthomosaics. Smaller areas of interest would produce fewer images that would lessen the time of processing if this is allowable within the scope of future projects (i.e. smaller forest stand management).

There were great differences between the processing times between many of the sets of imagery. This is believed to be the result of a combination of features including the number of images, the resolution of the image, the number of tie points produced and the accuracy of the ground control. It is a complicated process that cannot be easily defined by one causal factor. It was believed that the number of images, more specifically the number of pixels, has the greatest effect on processing time, while other features (tie points, ground control, etc.) have smaller individual effects (Remondino et al., 2014). There is also a difference between pixel sizes between datasets which affects the number of pixels per image, creating a more complicated algorithm to predict processing time.

The most novel approach in this process was the method by which the automated segmentation was performed. Object based image analysis (OBIA) has been used for a great number of applications in remote sensing but these procedures challenged these methods with a set of very complex features (Husson et al., 2016). The segmentation is the limiting factor by which volume estimates and other forest metrics can be derived. The results of the segmentations performed for this project were not as accurate as in less complex stands. Deng et al. (2016) showed a segmentation success rate of a 
predominately broadleaved stand at $71.8 \%$ using a combination of LiDAR data and true color imagery of coarser resolution (9.8 in) than what was produced in this study. Hernandez et al. (2016) produced tree detection results of $100 \%$ in a stone pine (Pinus pinea L.) plantation with a spacing of $32.8 \times 52.5 \mathrm{ft}$. Stone pine is distinctive for its flat-topped, umbrella like crowns which are very unique in open canopy forests. The imagery in this study was collected with a professional fixed wing UAV. Kuzmin et al. (2017) produced segmentation and classification results of $81.9 \%$ in boreal forests with only $30-70 \%$ canopy cover dominated by Norway spruce and Scots pine. For the current study, the greatest accuracy of 43 percent in the fall and summer composite image is promising. With consumer grade technology, 43 percent of tree crowns were able to be segmented properly in a very complex canopy for feature extraction. The increase in accuracy from the single fall and summer images to the composite image was as great as $20 \%$ for HLO, showing the importance of capturing as much data as. But, the issues with eCognition parameters not easily being transferred between images makes this process difficult to replicate on other sites.

An explanation for the difference in segmentation quality between sites could be influenced by sites themselves. HLO was split between north and south facing aspects with the north facing aspects being dominated by red maple and yellow-poplar, while HL3 was predominately south and southwest facing aspects containing primarily mixed oak species (Table 8).

Table 8. Summary of species prevalence between HLO and HL3. The top three most prevalent species in each site are displayed.

\begin{tabular}{ccc}
\hline & HLO & HL3 \\
\hline \hline Total Number of Species & 15 & 11 \\
Top Species & RM (38\%) & RO (33\%) \\
Second Species & YP (17\%) & RM (32\%) \\
Third Species & CO (11\%) & CO (16\%) \\
Total \% of Top 3 & 66 & 81 \\
\% Oak & 29 & 56 \\
\hline
\end{tabular}


HL3 has fewer species and is more homogenous than HLO. More than on half of the species composition is comprised of the oak group. The more homogeneous a high density canopy is, the more difficult the segmentation becomes to an extent. Although there are only 11 total species and much of HL3 is dominated by three species, these species have variable crown shapes and the mixture of additional species makes it difficult to recognize for segmentation. Conifers have unique and easily identifiable crown shapes from an aerial view as compared to broadleaved trees (Deng et al, 2016). The dominance of HL3 by entirely broadleaved trees makes the complexity greater than most studies that have been published in this field but not as great as HLO. This difficulty to segment broadleaved trees due to their interwoven crowns is consistent with previous results (Ayrey et al., 2017).

The prevalence of oak species in HL3 is a glimpse into why this site was more poorly segmented due to the difficulty of segmenting individual oak tree crowns. Segmentation was made particularly difficult due to the fact that these oak crowns are not as homogenous in color as they would be without cicada damage. The hatching of brood five of the 17-year cicadas (Magicicada septendecium) throughout the north central portion of West Virginia during the data collection period caused an obvious amount of damage to many tree crowns. The damage was mostly observed in white oak species (chestnut oak and white oak). The brown color and discoloration in some pixels due to the cicadas are an added element of information that could potentially be disruptive to the segmentation process. Visual assessment of oak crown delineation showed poor segmentation quality on these individuals. Fall color did not have great effect for HL3 imagery, the lower species diversity made fall color discrimination less effective.

It also appears that there may be too much information for the segmentation to be performed when three sets of images are stacked as was done in HL3, specifically the inclusion of the early fall imagery in the 12 band image stack. The variability of this dataset may be a cause for the distinct decline in success for HL3 segmentations. This could also be due to the fact that it is difficult for the software to 
group pixels into similar groups (objects) when each of the pixels is represented by so much information, some of it may even be contradictory as colors change in seasons. Although there are numerous bands available, these data differ from hyperspectral because they have different acquisition times while hyperspectral has one. There was not a single individual season that captured the segmentation best, but the most accurate spatial measurements after segmentation (i.e. tree height) can be taken from fall imagery as was shown by the fall seasonal imagery for both sites had the lowest RMSE ( $15.0 \mathrm{ft}$ for HLO fall and $1.61 \mathrm{ft}$ for HL3 late fall). This is believed to be due to the greater visibility of the ground for development of tie points and referencing during the HL3 late fall acquisition.

The DBH derived from the relationship between diameter and crown area from field data was not strong. This relationship lacked data inputs from smaller trees as only co-dominant and dominant trees were measured. There were also only a limited number of large trees, with large crowns, measured on the ground. This equation operates under the assumption that all individual stems have the same access to growing spaces and resources which is far from reality in natural stands. The inclusion of more metrics for each of the individuals such as total tree height could improve this model relationship. The merchantable heights derived from the predictive equation from Brooks and Wiant (2006) were faced with inherent error due to the poor performance of crown area as a predictor of DBH. Remotely sensed forest volume estimates only seldom have been addressed in literature let alone attempts to estimate board foot volumes so there a few studies to compare these methods (Puliti et al., 2015). Messinger et al. (2016) were able to produce above ground carbon estimates of amazon forests with error values as low as $0.05 \%$. These numbers are comparable to other studies that have studied biomass estimation in eastern forests (Wu et al., 2016) and this is not a surprise that the accuracy of these estimates is greater than that of merchantable tree volumes. This measure was coarser than what was performed in this study and does not take in to account a great number of details necessary to evaluate useable board foot volumes. The allometric relationships studied for above 
ground carbon biomass are better understood than the relationships necessary for merchantable volumes (Radtke et al., 2017). Although there is error involved in the volume estimates produced from this study, an essential framework has been laid for future work.

Evaluation of image segmentations was a challenge without a fully defined reference dataset. The area of coverage was far too great to develop a full reference dataset. The lack of reference data in this study required the development of an objective as possible system of steps in order to compare the different seasonal segmentations. The method of visually evaluating segmentation fit contains subjectivity as compared to measuring the amount of overlap between segments which is common when reference data is available (Clinton et al., 2010). This method could be improved by increasing the number of test segmentations and filtering out segmentations of negligible size. It may also be prudent in the future to classify the error associated with the segmentation by defining whether the individual tree was over segmented, under segmented or misinterpreted. This provides the user more information for future segmentations.

Aerial imagery data collected in this study are viewed as a success for many of this study's objectives. The high resolution imagery supplied a visualization of forest health and sudden changes such as with the recent damage caused by the large 17-year cicada outbreak (Figure 15). 


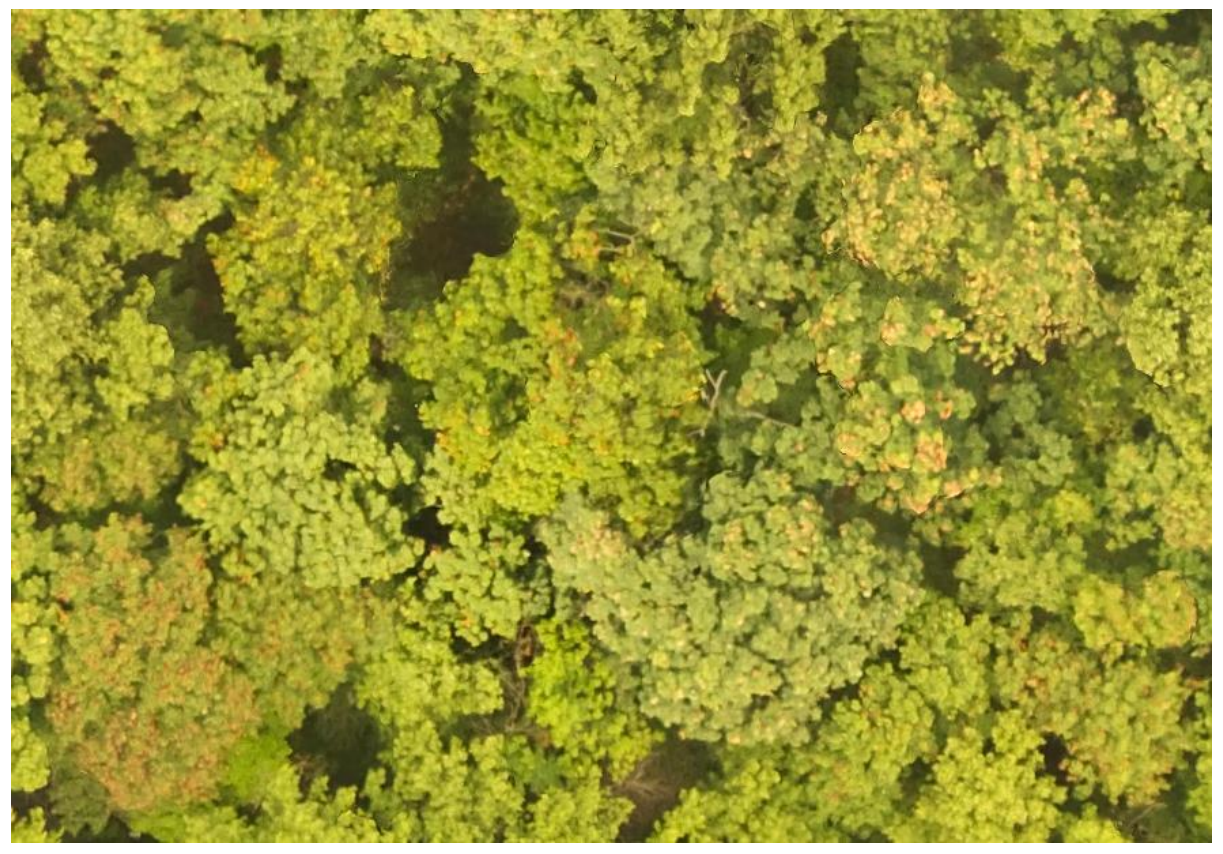

Figure 15. Example of crown damage caused by 17-year cicada outbreak of the summer of 2016. The brown blemishes on the summer leaf on-images were caused during this season and it was a goal of the team to capture the height of this damage.

Pixel values with certain colors of brown, representative of the damage, could be queried and counted to calculate an area affected by these individuals. The resolution is so high that other forest health issues can be mapped (e.g. a gypsy moth (Lymantria dispar) outbreak). The successful gap detection was promising as well, these gaps allow mangers a glimpse to the structure of the forest underneath the canopy and the succession of the forest. An increase in forest gaps, that are continually filled, allude to the transition between forest successive stages and the creation of a method to monitor this change from above would be highly valuable to managers. In particular, the number of canopy gaps is especially important habitat for forest songbirds such as the cerulean warbler (Setophaga cerulea), a federal species of concern (Perkins \& Wood, 2014). There was no significant statistical evidence that an individual season was greater than another at detecting gaps but summer imagery in HLO did have the greatest success rate at $80 \%$. The average difference between overall gap identification and queried gaps in $H L 3$, the failure to identify gaps in the query, may be a small reason why volume numbers were inflated for this site. 
The most distinct limitation to this process was the high cost of necessary software. An Agisoft Photoscan Professional license costs $\$ 3,499$ and an eCognition Developer commercial license costs $\$ 20,880$. Other limitations include the intensive ground control requirement necessitates expensive GPS equipment and labor and difficulties navigating the UAS policies of the Federal Aviation Administration. It is important to note that although UAS imagery acquisition is highly flexible, this also produces issues with transferable data between studies. The time at which imagery should be captured is highly specific to areas due to local weather patterns and lighting schemes as well as extreme differences in topography. Some canopies demand higher resolution at a lower flight altitude than others, and some topography is very complex and needs greater overlap to capture the complexities. It was also difficult to capture exact phenological changes. Elevation and variable levels of moisture from season to season make the peak season changes difficult to capture. If phenological events are of interest for future studies, multi-temporal data is essential. Segmentation accuracy is also a primary limit to the advancement of these methods. Creating segmentations of greater quality will need to be the emphasis moving forward for this type of work to be viable.

Future work for this study will target the use of new sensors compatible with UAS to create a dataset that promotes greater ease of segmentation. The use of a hyperspectral sensor would promote the identification of individual crowns using unique spectral signatures and this work would also aid in the classification of species which would provide an essential piece to completing an entire UAS derived forest inventory. The combination of spectral and UAS derived point cloud data was used to segment and classify individual trees in Finland to accuracies of 95\% (Nevalainen et al., 2017). Nevalainen et al. (2017) states that at time of submission their study was the only investigation into boreal forest species classification using the combination of hyperspectral data and UAS point clouds. 


\section{Conclusion}

Difficulties and time constraints prevented researchers from completing the processing of all five sites intended for this study but the findings presented from the two sites are valuable for future studies. It is important to capture phenology as close to the peak as possible to give a multi-temporal dataset the most information for differentiating for segmentation technology. It is essential to complete data collection with an $85 \%$ overlap in multiple directions to allow for the greatest number of tie points and most reliability in measurements from these data. The target areas should not exceed 75 acres for the use with a consumer grade multicopter UAS and preferably fewer acres should be targeted as data collection with this device is not fast enough to capture these data easily without lighting schemes changing even within the optimal lighting window. Time necessary for ground control could be reduced by the use of remote referencing techniques that need to be tested for these conditions. Inertial measurement unit remote referencing techniques could remove the only task that requires entering the stand physically (Wallace et al., 2012b) or the use of RTK PPP technology that is newly being used for aerial triangulation could be used in this same approach (Shi et al., 2016). Winter and spring seasons need to also be collected for each site to gain insight on whether seasonality truly has an effect on segmentation quality. But from the findings in this study there is no significant difference between fall or summer seasonal imagery or a composite image for segmentation quality.

Volume estimates derived from segmentation results are currently unreliable due to the poor quality of segmentation and deficiencies in estimates of trees per acre, merchantable height and dimeter. Improvements in segmentation quality need to be the primary focus in future work either through introduction of more advanced sensors or through the development of a more objective method for optimizing eCognition segmentation parameters. Segmentation results can vary by site conditions (e.g. slope, aspect, terrain, etc.). It is important to note that an increased ability of these methods to segment tree crowns may be a sign of species diversity. Complex canopies with interlacing crowns that have more homogenous species are more difficult to segment such was the case on HL3. It 
is important to design stands that are consistent throughout, whether there are high levels of variation or not, to ensure issues with segmentation do not occur.

These methods are not currently sound enough to replace forest managers or forest inventory crews but are in a position to compliment the process. Quick mobilization of these tools to capture postharvest stand density or effect of deer browse on regenerating stands is a valuable information for managers. Entering stands post-harvest is a difficult and tedious process and is sometimes abandoned all together due to the tangle of tops and sometimes few residual stems to be inventoried. These methods could be tailored heavily to removing the need for post-harvest cruises or aiding in the decision when these cruises are entirely necessary. Forest volume evaluation of stands such as the ones that were evaluated today could potentially be performed if segmentation quality was improved. If this is the case, the identification of individual crowns and their spatial location could allow a glimpse at the stand density and stocking levels, another very important management tool. It is likely that improvements in these methods will come with improvements in technology and optimization of software parameters.

There are a number of improvements that could be addressed in future work for this study area that could greatly improve the segmentation quality and the estimation of forest stand characteristics. The segmentation error is the most distinct issue in this project and addressing ways to improve this should be the primary emphasis of future work. Without accurate estimates of the number of tree crowns that exist in a forest stand, the number of stems cannot be accurately assessed. The number of trees in a stand is a pivotal piece of information in conducting forest inventory. The use of hyperspectral data flown on UAS would be an addition to the dataset that would provide researchers a new perspective on the question of how much data and what kinds of data are really the best for performing a tree crown segmentation in mixed hardwoods. The use of stands of varying stem densities would also be of use to evaluate the threshold of stand density that these methods are suitable. These stands could be open plantations, thinned stands or stands that had undergone intermediate treatments like timber 
stand improvement or shelterwood harvest techniques. The question of how high of spatial resolution is necessary for quality segmentation has yet to be answered and should be addressed in future studies.

Another approach to improve segmentation could be to set eCognition parameters to intentionally oversegment the tree crowns and then manually merge some polygons that represent a single tree crown. This would be a less autonomous process but may yield better results.

Addressing the lack of species level data for this study would also be a need for future improvements. Without this data, the inventory cannot be completed with each species having different form characteristics affecting the volume of the trees as well as monetary values for individual trees. Improvements to the relationships of crown area to DBH as well as how merchantable height is derived need to be improved. The crown area and DBH relationship may be improved by separating out site specific crown and DBH data to produce a dataset that is specific to each site. Introducing total height into that equation may also improve this relationship. The use of SfM and LiDAR derived total height measurements and their relationships to merchantable height, using field total height and merchantable height ratios for each specific site, may be an approach that would yield better results than utilizing species specific coefficients and an estimated DBH to predict merchantable height.

The creation of a reference dataset for even small areas throughout the five research sites should be another focus for future studies. A reference dataset would allow researchers to more objectively evaluate segmentation quality. This could be done through accurate field GPS measurements of tree crown locations or using stands of lesser density and apply another segmentation method such as the local maxima watershed segmentation method. A comparison between these two common segmentation methods should also be assessed to understand if the use of photogrammetric methods or the use of primarily the SfM would be the best approach for segmentation. The collection of winter and spring imagery should also be performed to complete the seasonal dataset and perform a more robust test on which time is best to implement these methods for a forest inventory. 


\section{Literature Cited}

Ayrey, E., Fraver, S., Kershaw Jr, J. A., Kenefic, L. S., Hayes, D., Weiskittel, A. R., \& Roth, B. E. (2017). Layer Stacking: A Novel Algorithm for Individual Forest Tree Segmentation from LiDAR Point Clouds. Canadian Journal of Remote Sensing, 1-13.

Berni, J. A. J., Zarco-Tejada, P. J., Suárez, L., González-Dugo, V., \&Fereres, E. (2009). Remote sensing of vegetation from UAV platforms using lightweight multispectral and thermal imaging sensors. Int. Arch. Photogramm. Remote Sens. Spatial Inform. Sci, 38(6).

Brandtberg, T., Warner, T. A., Landenberger, R. E., \& McGraw, J. B. (2003). Detection and analysis of individual leaf-off tree crowns in small footprint, high sampling density lidar data from the eastern deciduous forest in North America. Remote sensing of Environment, 85(3), 290-303.

Brooks, J. R., \& Wiant, H. V. (2006). A simple technique for estimating board foot volume yields in Appalachian hardwoods. Northern Journal of Applied Forestry, 23(3), 211-214.

Burkholder, A., Warner, T. A., Culp, M., \& Landenberger, R. (2011). Seasonal trends in separability of leaf reflectance spectra for Ailanthus altissima and four other tree species. Photogrammetric Engineering \& Remote Sensing, 77(8), 793-804.

Cochrane, M. A. (2000). Using vegetation reflectance variability for species level classification of hyperspectral data. International Journal of Remote Sensing, 21(10), 2075-2087.

Clinton, N., Holt, A., Scarborough, J., Yan, L., \& Gong, P. (2010). Accuracy assessment measures for object-based image segmentation goodness. Photogrammetric Engineering and remote sensing, 76(3), 289-299.

Cruz, H., Eckert, M., Meneses, J., \& Martínez, J. F. (2016). Efficient forest fire detection index for application in unmanned aerial systems (UASs). Sensors, 16(6), 893.

Dalponte, M., Ørka, H. O., Gobakken, T., Gianelle, D., \& Næsset, E. (2013). Tree species classification in boreal forests with hyperspectral data. IEEE Transactions on Geoscience and Remote Sensing, 51(5), 2632-2645.

Deng, S., Katoh, M., Yu, X., Hyyppä, J., \& Gao, T. (2016). Comparison of Tree Species Classifications at the Individual Tree Level by Combining ALS Data and RGB Images Using Different Algorithms. Remote Sensing, 8(12), 1034.

Ek, A. R., Birdsall, E. T., \& Spears, R. J. (1984). A simple model for estimating total and merchantable tree heights.

Gering, L. R., \& May, D. M. (1995). The relationship of diameter at breast height and crown diameter for four species groups in Hardin County, Tennessee. Southern Journal of Applied Forestry, 19(4), 177-181.

Getzin, S., Wiegand, K., \&Schöning, I. (2012). Assessing biodiversity in forests using very high-resolution images and unmanned aerial vehicles. Methods in Ecology and Evolution, 3(2), 397-404.

Haala, N., Cramer, M., \&Rothermel, M. (2013). Quality of 3D point clouds from highly overlapping UAV imagery. ISPRS-International Archives of the Photogrammetry, Remote Sensing and Spatial Information Sciences XL-1 W, 2, 183-188. 
Haque, M. E., Al-Ramadan, B., \& Johnson, B. A. (2016). Rule-based land cover classification from very high-resolution satellite image with multiresolution segmentation. Journal of Applied Remote Sensing, 10(3), 036004-036004.

Hemery, G. E., Savill, P. S., \& Pryor, S. N. (2005). Applications of the crown diameter-stem diameter relationship for different species of broadleaved trees. Forest Ecology and Management, 215(1), 285294.

Hernandez, J. G., Gonzalez-Ferreiro, E., Sarmento, A., Silva, J., Nunes, A., Correia, A. C., Fontes, L., Tome, M., \& Diaz-Varela, R. (2016). Short Communication. Using high resolution UAV imagery to estimate tree variables in Pinuspinea plantation in Portugal. Forest Systems, 25(2), 09.

Honer, T. G. (1964). The use of height and squared diameter ratios for the estimation of merchantable cubic foot volume. The Forestry Chronicle, 40(3), 324-331.

Hrůza, P., Mikita, T., \& Janata, P. (2016). Monitoring of Forest Hauling Roads Wearing Course Damage using Unmanned Aerial Systems. Acta Universitatis Agriculturae et Silviculturae Mendelianae Brunensis, 64(5), 1537-1546.

Husson, E., Ecke, F., \& Reese, H. (2016). Comparison of Manual Mapping and Automated Object-Based Image Analysis of Non-Submerged Aquatic Vegetation from Very-High-Resolution UAS Images. Remote Sensing, 8(9), 724.

Jing, L., Hu, B., Li, J., \& Noland, T. (2012). Automated delineation of individual tree crowns from LiDAR data by multi-scale analysis and segmentation. Photogrammetric Engineering \& Remote Sensing, 78(12), 1275-1284.

Kangas, A., \&Maltamo, M. (Eds.). (2006). Forest inventory: methodology and applications (Vol. 10). Springer Science \& Business Media.

Keane, J. F., \&Carr, S. S. (2013). A brief history of early unmanned aircraft. Johns Hopkins APL Technical Digest, 32(3), 558-571.

Key, T., Warner, T. A., McGraw, J. B., \&Fajvan, M. A. (2001). A comparison of multispectral and multitemporal information in high spatial resolution imagery for classification of individual tree species in a temperate hardwood forest. Remote Sensing of Environment, 75(1), 100-112.

Kim, S., McGaughey, R. J., Andersen, H. E., \&Schreuder, G. (2009). Tree species differentiation using intensity data derived from leaf-on and leaf-off airborne laser scanner data. Remote Sensing of Environment, 113(8), 1575-1586.

Kuzmin, A., Korhonen, L., Manninen, T., \&Maltamo, M. (2017). Automatic Segment-Level Tree Species Recognition Using High Resolution Aerial Winter Imagery. European Journal of Remote Sensing, 49, 239259.

Kwak, D. A., Lee, W. K., Lee, J. H., Biging, G. S., \& Gong, P. (2007). Detection of individual trees and estimation of tree height using LiDAR data. Journal of Forest Research, 12(6), 425-434.

Lillesand, T., Kiefer, R. W., \& Chipman, J. (2014). Remote sensing and image interpretation. John Wiley \& Sons. 
Lisein, J., Michez, A., Claessens, H., \& Lejeune, P. (2015). Discrimination of deciduous tree species from time series of unmanned aerial system imagery. PloS one, 10(11), e0141006.

Lockhart, B. R., Weih Jr, R. C., \& Smith, K. M. (2005). Crown radius and diameter at breast height relationships for six bottomland hardwood species. Journal of the Arkansas Academy of Science, 59(1), 110-115.

Medhurst, J. L., \& Beadle, C. L. (2001). Crown structure and leaf area index development in thinned and unthinned Eucalyptus nitens plantations. Tree physiology, 21(12-13), 989-999.

Messinger, M., Asner, G. P., \&Silman, M. (2016). Rapid Assessments of Amazon Forest Structure and Biomass Using Small Unmanned Aerial Systems. Remote Sensing, 8(8), 615.

Michez, A., Piégay, H., Lisein, J., Claessens, H., \& Lejeune, P. (2016). Classification of riparian forest species and health condition using multi-temporal and hyperspatial imagery from unmanned aerial system. Environmental monitoring and assessment, 188(3), 1-19.

Mikita, T., Janata, P., \&Surový, P. (2016). Forest stand inventory based on combined aerial and terrestrial close-range photogrammetry. Forests, 7(8), 165.

Nevalainen, O., Honkavaara, E., Tuominen, S., Viljanen, N., Hakala, T., Yu, X., Hyyppa, J., Saari, H., Polonen, I., \& Tommaselli, A. M. (2017). Individual Tree Detection and Classification with UAV-Based Photogrammetric Point Clouds and Hyperspectral Imaging. Remote Sensing, 9(3), 185.

Newcome, L. R. (2004). Unmanned aviation: a brief history of unmanned aerial vehicles. Aiaa.

Orka, H. O., Næsset, E., \&Bollandsas, O. M. (2009). Classifying species of individual trees by intensity and structure features derived from airborne laser scanner data. Remote Sensing of Environment, 113(6), 1163-1174.

Perkins, K. A., \& Wood, P. B. (2014). Selection of forest canopy gaps by male Cerulean Warblers in West Virginia. The Wilson Journal of Ornithology, 126(2), 288-297.

Puliti, S., Orka, H. O., Gobakken, T., \&Næsset, E. (2015). Inventory of small forest areas using an unmanned aerial system. Remote Sensing, 7(8), 9632-9654.

Radtke, P., Walker, D., Frank, J., Weiskittel, A., DeYoung, C., MacFarlane, D., Domke, G., Woodall, C., Coulston, J., \& Westfall, J. (2017). Improved accuracy of aboveground biomass and carbon estimates for live trees in forests of the eastern United States. Forestry, 90(1), 32-46.

Remondino, F., Spera, M. G., Nocerino, E., Menna, F., \& Nex, F. (2014). State of the art in high density image matching. The Photogrammetric Record, 29(146), 144-166.

Shi, J., Yuan, X., Cai, Y., \& Wang, G. (2016). GPS real-time precise point positioning for aerial triangulation. GPS Solutions, 1-10.

Stubberud, S., \& Kramer, K. (2009). Target data association using a fuzzy-logic based approach. INTECH Open Access Publisher.

Suratno, A., Seielstad, C., \& Queen, L. (2009). Tree species identification in mixed coniferous forest using airborne laser scanning. ISPRS Journal of Photogrammetry and Remote Sensing, 64(6), 683-693. 
Tiede, D., Hochleitner, G., \&Blaschke, T. (2005, August). A full GIS-based workflow for tree identification and tree crown delineation using laser scanning. In ISPRS Workshop CMRT (Vol. 5, No. 2930.08, p. 2005).

Turner, D., Lucieer, A., \& Wallace, L. (2014). Direct georeferencing of ultrahigh-resolution UAV imagery. IEEE Transactions on Geoscience and Remote Sensing, 52(5), 2738-2745.

Varo-Martínez, M. Á., Navarro-Cerrillo, R. M., Hernández-Clemente, R., \& Duque-Lazo, J. (2017). Semiautomated stand delineation in Mediterranean Pinus sylvestris plantations through segmentation of LiDAR data: The influence of pulse density. International Journal of Applied Earth Observation and Geoinformation, 56, 54-64.

Wallace, L., Lucieer, A., \& Watson, C. (2012a). Assessing the feasibility of UAV-based LiDAR for high resolution forest change detection. Proc. ISPRS, Int. Archives Photogramm., Remote Sens. Spatial Inf. Sci, 38, B7.

Wallace, L., Lucieer, A., Watson, C., \& Turner, D. (2012b). Development of a UAV-LiDAR system with application to forest inventory. Remote Sensing, 4(6), 1519-1543.

Wallace, L., Lucieer, A., Malenovský, Z., Turner, D., \&Vopěnka, P. (2016). Assessment of Forest Structure Using Two UAV Techniques: A Comparison of Airborne Laser Scanning and Structure from Motion (SfM) Point Clouds. Forests, 7(3), 62.

Wei, L., Yang, B., Jiang, J., Cao, G., \& Wu, M. (2016). Vegetation filtering algorithm for UAV-borne lidar point clouds: a case study in the middle-lower Yangtze River riparian zone. International Journal of Remote Sensing, 1-12.

White, J. C., Wulder, M. A., Vastaranta, M., Coops, N. C., Pitt, D., \& Woods, M. (2013). The utility of image-based point clouds for forest inventory: A comparison with airborne laser scanning. Forests, 4(3), 518-536.

Whitehead, K., Hugenholtz, C. H., Myshak, S., Brown, O., LeClair, A., Tamminga, A., Barachyn, T., Moorman, B. \& Eaton, B. (2014). Remote sensing of the environment with small unmanned aircraft systems (UASs), part 2: scientific and commercial applications 1. Journal of unmanned vehicle systems, 2(3), 86-102.

Wu, Z., Dye, D., Vogel, J., \& Middleton, B. (2016). Estimating forest and woodland aboveground biomass using active and passive remote sensing. Photogrammetric Engineering \& Remote Sensing, 82(4), 271281.

Yang, J., He, Y., \& Caspersen, J. (2017). Region merging using local spectral angle thresholds: A more accurate method for hybrid segmentation of remote sensing images. Remote Sensing of Environment, 190, 137-148.

Zawawi, A. A., Shiba, M., \&Jemali, N. J. N. (2015). Accuracy of LiDAR-based tree height estimation and crown recognition in a subtropical evergreen broad-leaved forest in Okinawa, Japan. Forest Systems, 24(1), 002.

Zhang, K., Robinson, J., \& Jing, L. (2016, July). Canopy vertical parameters estimation using unmanned aerial vehicle (UAV) imagery. In Geoscience and Remote Sensing Symposium (IGARSS), 2016 IEEE International (pp. 2276-2279). IEEE. 